\title{
Safety and Therapeutic Efficacy of Thymoquinone-Loaded Liposomes against Drug-Sensitive and Drug-Resistant Acinetobacter baumannii
}

\author{
Khaled S. Allemailem ${ }^{1}{ }^{\oplus}$, Abdullah M. Alnuqaydan ${ }^{2}$, Ahmad Almatroudi $^{1}{ }^{(D}$, Faris Alrumaihi $\left.{ }^{1}{ }^{(}\right)$, \\ Aseel Aljaghwani ${ }^{1}$, Habibullah Khalilullah ${ }^{3}$, Hina Younus ${ }^{4}$, Arif Khan ${ }^{5}(\mathbb{D})$ and Masood A. Khan ${ }^{5, *(1)}$ \\ 1 Department of Medical Laboratories, College of Applied Medical Sciences, Qassim University, \\ Buraydah 51452, Saudi Arabia; k.allemailem@qu.edu.sa (K.S.A.); aamtrody@qu.edu.sa (A.A.); \\ f_alrumaihi@qu.edu.sa (F.A.); aseel708@hotmail.com (A.A.) \\ 2 Department of Medical Biotechnology, College of Applied Medical Sciences, Qassim University, \\ Buraydah 51452, Saudi Arabia; ami.alnuqaydan@qu.edu.sa \\ 3 Department of Pharmaceutical Chemistry \& Pharmacognosy, Unaizah College of Pharmacy, \\ Qassim University, Buraydah 51452, Saudi Arabia; shabib79@gmail.com \\ 4 Interdisciplinary Biotechnology Unit, Aligarh Muslim University, Aligarh 202002, India; \\ hinayounus@rediffmail.com \\ 5 Department of Basic Health Sciences, College of Applied Medical Sciences, Qassim University, \\ Buraydah 51452, Saudi Arabia; 4140@qu.edu.sa \\ check for \\ updates \\ * Correspondence: a_khan@qu.edu.sa; Tel.: +966-507059437; Fax: +966-63801628
}

Citation: Allemailem, K.S.;

Alnuqaydan, A.M.; Almatroudi, A.; Alrumaihi, F.; Aljaghwani, A.; Khalilullah, H.; Younus, H.; Khan, A.; Khan, M.A. Safety and Therapeutic Efficacy of Thymoquinone-Loaded Liposomes against Drug-Sensitive and Drug-Resistant Acinetobacter baumannii. Pharmaceutics 2021, 13, 677. https:// doi.org/10.3390/pharmaceutics13050677

Academic Editors: Rafael VazquezDuhalt, Karla Juarez-Moreno, Josué D. Mota-Morales and Franco Dosio

Received: 10 March 2021

Accepted: 4 May 2021

Published: 8 May 2021

Publisher's Note: MDPI stays neutral with regard to jurisdictional claims in published maps and institutional affiliations.

\section{Copyright: (c) 2021 by the authors.} Licensee MDPI, Basel, Switzerland. This article is an open access article distributed under the terms and conditions of the Creative Commons Attribution (CC BY) license (https:// creativecommons.org/licenses/by/ $4.0 /)$.
Abstract: In the present study, we investigated the activity of free thymoquinone (TQ) or liposomal thymoquinone (Lip-TQ) in comparison to standard antibiotic amoxicillin (AMX) against the drugsensitive and drug-resistant Acinetobacter baumannii. A liposomal formulation of TQ was prepared and characterized and its toxicity was evaluated by analyzing the hematological, liver and kidney function parameters. TQ was effective against both drug-sensitive and drug-resistant A. baumannii as shown by the findings of drug susceptibility testing and time kill kinetics. Moreover, the therapeutic efficacy of TQ or Lip-TQ against A. baumannii was assessed by the survival rate and the bacterial load in the lung tissues of treated mice. The mice infected with drug-sensitive A. baumannii exhibited a $90 \%$ survival rate on day 30 post treatment with Lip-TQ at a dose of $10 \mathrm{mg} / \mathrm{kg}$, whereas the mice treated with AMX (10 mg/kg) had a 100\% survival rate. On the other hand, the mice infected with drugresistant $A$. baumannii had a $70 \%$ survival rate in the group treated with Lip-TQ, whereas AMX was ineffective against drug-resistant $A$. baumannii and all the mice died within day 30 after the treatment. Moreover, Lip-TQ treatment effectively reduced the bacterial load in the lung tissues of the mice infected with the drug-sensitive and drug-resistant $A$. baumannii. Moreover, the blood of the mice treated with Lip-TQ had reduced levels of inflammation markers, leukocytes and neutrophils. The results of the present study suggest that Lip-TQ may prove to be an effective therapeutic formulation in the treatment of the drug-sensitive or drug-resistant A. baumannii infection as well.

Keywords: Acinetobacter baumannii; thymoquinone; liposome; inflammation; drug-resistant

\section{Introduction}

Acinetobacter baumannii has lately emerged as an important opportunistic pathogen for the skin, bloodstream and urinary tract infections [1]. The use of catheters, endotracheal intubation and immune suppression have been considered the main risk factors associated with A. baumannii infections [2]. Currently, it poses major health problems due to a sudden upsurge in the numbers of antibiotic-resistant $A$. baumannii isolates that are mounting a serious challenge to clinicians and researchers. Lately, carbapenem-resistant isolates of A. baumannii have surfaced in many parts of the world [3]. Aly et al. demonstrated that among all the A. baumannii isolates reported from 2006 to 2008 at King Abdulaziz 
Medical City Hospital in Riyadh, Saudi Arabia, 79.1\% exhibited resistance to imipenem and $92.1 \%$ - to meropenem [4]. In another study, Saeed et al. showed that $93 \%$ of all the A. baumannii isolates exhibited resistance to piperacillin/tazobactam, $92 \%$ - to ciprofloxacin, $96 \%$ - to amoxicillin/clavulanic acid [5]. Overall, these reports warn us that A. baumannii is developing antibiotic resistance very fast and is going to pose a big threat to humanity in the coming years. It adopts various drug resistance mechanisms, including the development of efflux pumps, beta-lactamase enzymes, changes in the outer membrane and penicillinbinding proteins [6].

The seeds of Nigella sativa, commonly known as black seed or black cumin, have been widely used in the Arabic, Ayurveda, Chinese and Unani systems of medicine [7-9] because $N$. sativa has numerous nutritional and medicinal benefits against cancer, diabetes, asthma, hypertension and eczema $[7,10]$. The black seed contains many important phytoconstituents, including thymoquinone, thymohydroquinone, dithymoquinone, carvacrol, thymol, nigellicine, nigellidine, p-cymene, etc. [8]. Thymoquinone (TQ), a chief constituent of black seed, targets multiple cell signaling pathways and has potential therapeutic implications in many diseases (Figure 1) [7]. Importantly, TQ exhibited the broadspectrum antimicrobial activity against various pathogens, including bacteria, fungi and viruses [7]. Moreover, TQ effectively inhibited biofilm formation in bacterial and fungal pathogens [11-13]. Interestingly, TQ inhibited the functioning of the drug efflux pumps in bacteria, including Pseudomonas aeruginosa, Staphylococcus aureus and Bacillus cereus [14]. In addition to their activity against bacteria and fungi, black seed and TQ also exhibited activity against many viruses, including mouse hepatitis virus (MHV)-A59, cytomegalovirus, hepatitis $\mathrm{C}$ virus (HCV) and avian influenza virus [15].

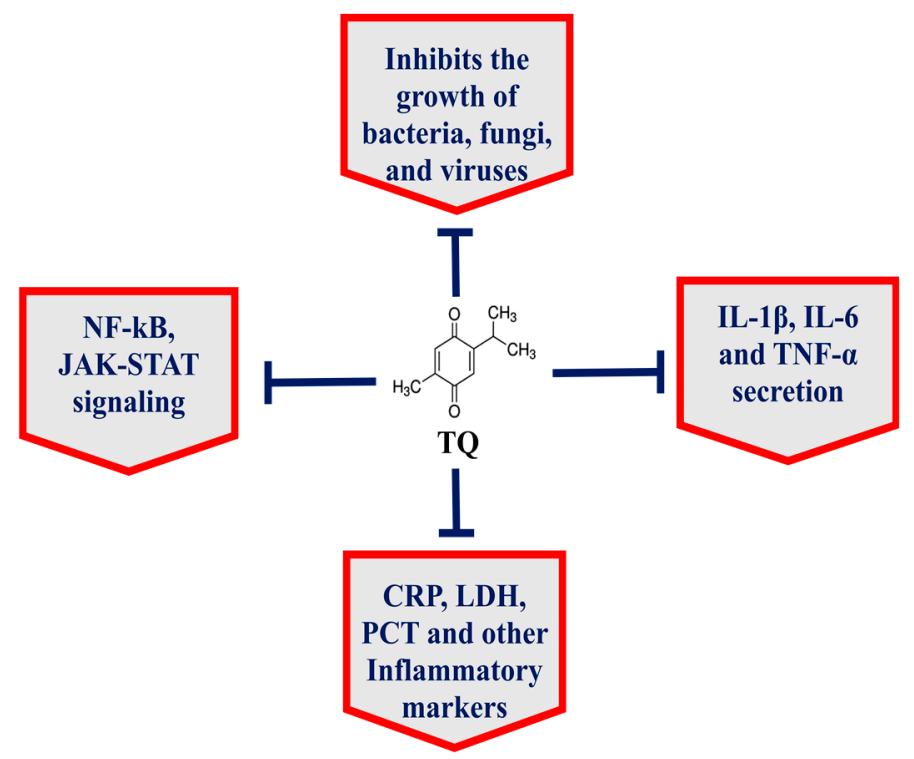

Figure 1. TQ exhibits multitargeting behavior in the treatment of various diseases.

Liposomes have been used as effective drug and vaccine delivery systems in model animals [16]. Moreover, the pegylation of lipid nanoparticles has been found to be more effective in selective organ targeting of antigens [17]. Because of its poor solubility in aqueous media, the therapeutic potential of TQ has not been adequately utilized. Incorporation of TQ in drug delivery systems has resulted in greater effectiveness and bioavailability [18]. TQ-incorporated liposomes inhibited the proliferation of breast cancer cells [16], whereas TQ-gold niosomes were effective in breaking drug resistance in MCF7 breast cancer cells [19]. Earlier, we demonstrated that liposomal TQ effectively combated fluconazole-resistant Candida albicans in a mouse model [20]. The present study aimed to develop a liposomal formulation of TQ (Lip-TQ) that can be effective in fighting both drug-sensitive and drug-resistant $A$. baumannii. Here, we determined both in vitro and 
in vivo activity of Lip-TQ against the drug-sensitive and drug-resistant $A$. baumannii. The results demonstrated that treatment with Lip-TQ was effective in curing the mice infected with the drug-sensitive and drug-resistant $A$. baumannii.

\section{Materials and Methods}

\subsection{Materials}

Liposome-grade cholesterol and 1,2-dipalmitoyl-Sn-glycero-3-phosphocholine (DPPC) were obtained from Avanti Polar Lipids (Alabaster, AL, USA). Nutrient agar and nutrient broth were procured from HiMedia (Mumbai, India). Thymoquinone was bought from Sigma-Aldrich (St. Louis, MO, USA). A mouse C-reactive protein (CRP) ELISA kit was obtained from Sigma-Aldrich (St. Louis, MO, USA). A mouse procalcitonin (PCT) ELISA kit was obtained from Cusabio Biotech (Carlsbad, CA, USA).

\subsection{Test Strain of Acinetobacter baumannii}

The drug-resistant strain of $A$. baumannii (ATCC 19606) was acquired from the American Type Culture Collection (ATCC, Manassas, VA, USA), whereas the drug-sensitive isolate was obtained from the Department of Microbiology, King Fahad Specialist Hospital, Buraydah, Saudi Arabia. Both strains were maintained on Mueller-Hinton agar (MHA) culture media plates.

\subsection{Screening of A. baumannii by Automated Susceptibility Testing}

The susceptibility testing of A. baumannii was performed according to the EUCAST guidelines similar to the CLSI 2016 guidelines [21,22]. Briefly, an A. baumannii suspension was adjusted to the turbidity equal to $0.5 \mathrm{McFarland}$ standard. Tryptone soy agar (TSA) plates (Oxoid Limited, Basingstoke, UK) were prepared and each plate was inoculated with $60 \mu \mathrm{L}$ of the A. baumannii suspension. Antibiotic discs (Oxoid Limited) were placed on TSA plates just after plate streaking. Consequently, the plates were kept in the incubator at $37^{\circ} \mathrm{C}$ for $24 \mathrm{~h}$ to observe the drug susceptibility testing. The following antibiotic discs were used to test the susceptibility of A. baumannii: ampicillin $(10 \mu \mathrm{g})$, chloramphenicol $(30 \mu \mathrm{g})$, cefotaxime $(30 \mu \mathrm{g})$, ceftriaxone $(30 \mu \mathrm{g})$, cotrimoxazole $(25 \mu \mathrm{g})$, cephalothin $(30 \mu \mathrm{g})$, clindamycin $(2 \mu \mathrm{g})$, nitrofurantoin $(300 \mu \mathrm{g})$, norfloxacin $(10 \mu \mathrm{g})$, ceftazidime $(30 \mu \mathrm{g})$, tobramycin $(10 \mu \mathrm{g})$, ciprofloxacin $(5 \mu \mathrm{g})$, nalidixic acid $(30 \mu \mathrm{g})$, imipenem $(10 \mu \mathrm{g})$ and piperacillin $(100 \mu \mathrm{g})$.

\subsection{Determination of In Vitro Activity of TQ against A. baumannii}

The activity of TQ against $A$. baumannii was determined by the agar well diffusion method and the broth macrodilution susceptibility method. Nutrient agar plates were prepared and seeded with the $A$. baumannii inoculum. The wells of 8-mm diameter were created and $50 \mu \mathrm{L}$ containing 25,50 and $100 \mu \mathrm{g}$ of TQ or amoxycillin (AMX) were loaded in each well. The plates were incubated at $37{ }^{\circ} \mathrm{C}$ for $24 \mathrm{~h}$. The activity of TQ against A. baumannii was determined by measuring the growth inhibition zone.

The minimum inhibitory concentration (MIC) of TQ against A. baumannii was determined by following the guidelines of the Clinical and Laboratory Standards Institute (CLSI) [21]. Various concentrations of TQ or AMX $(0.125$ to $128 \mu \mathrm{g} / \mathrm{mL})$ were used to determine their MIC against A. baumannii. A. baumannii was cultured in nutrient broth at $37^{\circ} \mathrm{C}$. After $24 \mathrm{~h}$, the cells were centrifuged and A. baumannii cells were suspended in nutrient broth to $0.5 \mathrm{McF}$ arland turbidity and added to tubes containing various concentrations of TQ or AMX. The tubes were incubated at $37{ }^{\circ} \mathrm{C}$ for $24 \mathrm{~h}$. The lowest concentration of TQ or AMX at which $A$. baumannii did not exhibit any turbidity was considered as the MIC of the drug.

The antibacterial activity of TQ or AMX was also observed through microscopic analysis. In a 24-well sterile culture plate, $1 \times 10^{6} \mathrm{CFUs}$ of $A$. baumannii were added to $1 \mathrm{~mL}$ nutrient broth at $37^{\circ} \mathrm{C}$. After $4 \mathrm{~h}$, TQ or AMX at the concentrations of $1,2.5$ and $5 \mu \mathrm{g} / \mathrm{mL}$ were added to the well containing the bacteria, whereas the well containing the vehicle 
was considered the negative control. After $24 \mathrm{~h}$ of incubation, the wells were washed with the phosphate-buffered saline (PBS) and observed under the microscope.

\subsection{Time-Kill Assay}

A time-kill assay was performed with $5 \times 10^{5} \mathrm{CFU} / \mathrm{mL}$ of $A$. baumannii with $1,2,4$ and $8 \mu \mathrm{g} / \mathrm{mL}$ of TQ or AMX as described earlier [23]. After overnight culture, A. baumannii was diluted with the Mueller-Hinton broth (MHB). This culture was incubated at $37^{\circ} \mathrm{C}$ until the log phase of growth was achieved. The A. baumannii suspension $\left(5 \times 10^{5} \mathrm{CFUs}\right)$ was transferred to flasks containing $20 \mathrm{~mL}$ of the $\mathrm{MHB}$ and the abovementioned amounts of TQ or AMX. Samples $(0.5 \mathrm{~mL})$ were taken in duplicates at the baseline and after 1, 3, 6, 12 and $24 \mathrm{~h}$. The samples were centrifuged at $12,000 \times g$ for $15 \mathrm{~min}$ and reconstituted with sterile PBS to the original volume to minimize any drug carryover effect. The numbers of bacteria were quantified by plating the serial dilutions onto Mueller-Hinton agar (MHA) plates and incubating them at $37^{\circ} \mathrm{C}$. The bacterial density of each sample was determined by counting the CFUs and the limit of detection was considered $100 \mathrm{CFU} / \mathrm{mL}$.

\subsection{Preparation of TQ-Loaded Liposomes}

DPPC, cholesterol and TQ were dissolved into the mixture of methanol and chloroform $(1: 1 \mathrm{v} / \mathrm{v})$ as described earlier [24]. The molar ratio of lipids and TQ was kept 10:1. All the ingredients were taken in a round bottom flask and the solvents were evaporated using a rotary evaporator to form a thin lipid film at $37^{\circ} \mathrm{C}$. It was subjected to vacuum to remove traces of the solvents. The film was hydrated with an appropriate amount of sterile PBS at $37^{\circ} \mathrm{C}$. The suspension was sonicated to prepare TQ-loaded liposomes. Free TQ was separated by centrifuging the suspension at $25,000 \times g$ for $30 \mathrm{~min}$.

\subsection{Characterization of Liposomes}

Liposomes were passed through a membrane $(100 \mathrm{~nm})$ using a mini-extruder device procured from Avanti Polar Lipids (Alabaster, AL, USA). The size and shape of liposomes were determined using transmission electron microscopy (Hillsboro, OR, USA). The samples were dropped on a carbon-coated copper grid with consequent staining and drying. The images were taken using a high-resolution TEM operating at $200 \mathrm{kV}$ [25]. The polydispersity index (PDI) of TQ-loaded liposomes was also analyzed using a Malvern Nano Zetasizer (Malvern Instruments, Southborough, MA, USA) employing the dynamic light scattering (DLS) technique as described earlier [25].

\subsection{Determination of $T Q$ Entrapment Efficiency $(E E)$ in Liposomes}

The quantity of TQ entrapped in liposomes was estimated by taking the absorbance at $330 \mathrm{~nm}$ [24]. An aliquot of liposomal TQ $(100 \mu \mathrm{L})$ was disrupted in DMSO and the released TQ was quantified using the standard curve of TQ. The percent $E E$ of TQ was calculated by estimating the entrapped TQ out of the total quantity of TQ added to the lipids.

$$
\% \mathrm{EE} \text { of TQ }=(\text { liposome-entrapped TQ } / \text { total TQ }) \times 100
$$

\subsection{Determination of Stability of Liposomes and Release Kinetics of $T Q$}

The stability of Lip-TQ was determined at $37^{\circ} \mathrm{C}$ as described earlier [26]. A sample $(1 \mathrm{~mL})$ of the liposomal suspension was placed in the cellulose dialysis tubing in $25 \mathrm{~mL}$ of sterile distilled water in a water bath maintained at $37{ }^{\circ} \mathrm{C}$ with constant slow stirring. At various time points $(1,2,3,6,12$ and $24 \mathrm{~h}), 1 \mathrm{~mL}$ of volume was taken from the beaker and $1 \mathrm{~mL}$ of fresh distilled water was added to maintain the original volume. The absorbance of the withdrawing aliquot was measured at $330 \mathrm{~nm}$ to determine the leakage of TQ.

The release kinetics of TQ from the liposomal formulation was determined by incubating the mixture consisting of one volume of Lip-TQ with nine volumes of human serum. The reaction mixtures were incubated for $1,2,3,6,12$ and $24 \mathrm{~h}$ at $37^{\circ} \mathrm{C}$ as described earlier [26]. The mixture was centrifuged at $12,000 \times g$ for $15 \mathrm{~min}$. The amount of TQ 
released from Lip-TQ into the serum was estimated as a percentage of total TQ present in the liposomes initially added to the serum.

\subsection{Mice}

Male Swiss mice (12-week-old) were taken from the animal house facility of the College of Applied Medical Sciences, Qassim University, Saudi Arabia. The experiments were conducted according to the guidelines and regulations of the animal ethics committee of the College of Applied Medical Sciences, Qassim University. Before the infection, the mice were anesthetized by injecting a mixture of ketamine $(90 \mathrm{mg} / \mathrm{kg})$ and xylazine $(10 \mathrm{mg} / \mathrm{kg})$ intraperitoneally. The infected mice were observed every day for their mortality and morbidity during the study period. This study was approved by the animal ethics committee (approval number 5604-cams1-2019-2-2-I, 19 December 2019).

\subsubsection{Determination of TQ Toxicity in Mice}

In order to determine toxicity, various doses of free TQ and Lip-TQ were administered to mice intraperitoneally for seven consecutive days. For in vivo administration, TQ was dissolved in DMSO and diluted with normal saline to have 1\% DMSO in the final solution. The mice were observed for any morbidity and mortality during this period. The mice were randomly divided into the following groups and each group contained six mice:
(1) Saline
(2) Sham liposomes
(3) Free TQ-1 mg/kg
(4) Free TQ- $10 \mathrm{mg} / \mathrm{kg}$
(5) Free TQ-20 mg/kg
(6) Free $\mathrm{TQ}-40 \mathrm{mg} / \mathrm{kg}$
(7) $\quad$ Lip-TQ-1 mg/kg
(8) $\quad \mathrm{Lip}-\mathrm{TQ}-10 \mathrm{mg} / \mathrm{kg}$
(9) Lip-TQ-20 mg/kg
(10) $\mathrm{Lip}-\mathrm{TQ}-40 \mathrm{mg} / \mathrm{kg}$

\subsubsection{Analysis of Hematological and Biochemical Parameters}

On day 8 , blood was collected from the mice of each group through a retroorbital puncture. The erythrocyte, leukocyte and platelet counts were determined. Moreover, the levels of AST (aspartate transaminase) and ALT (alanine transaminase) as liver inflammation markers were determined, whereas the values of creatinine and blood urea nitrogen (BUN) were determined as kidney function parameters [27].

\subsubsection{Standardization of $A$. baumannii Infection in Mice}

A. baumannii (ATCC 19606) were grown in a nutrient broth at $37^{\circ} \mathrm{C}$ for $24 \mathrm{~h}$. A. baumannii cells were centrifuged at $5000 \mathrm{rpm}$ for $15 \mathrm{~min}$ at $4{ }^{\circ} \mathrm{C}$. The cell pellet was washed twice with normal saline. The bacterial cells were counted and mice in various groups were infected with $1 \times 10^{6}, 5 \times 10^{6}, 1 \times 10^{7}, 5 \times 10^{7}, 1 \times 10^{8}$ CFUs of $A$. baumannii intravenously.

\subsubsection{Mouse Model of A. baumannii Infection}

After the standardization of the infection dose, each mouse was intravenously infected with $1 \times 10^{7}$ CFUs of $A$. baumannii.

\subsubsection{Treatment of $A$. baumannii-Infected Mice with TQ Formulations}

The efficacy of free or Lip-TQ $(1,5$ and $10 \mathrm{mg} / \mathrm{kg})$ was determined against $A$. baumannii in Swiss mice. After $12 \mathrm{~h}$ of the A. baumannii infection, the mice were treated with single daily doses of the TQ formulation for seven successive days. The mice were divided into eight groups and each group contained ten mice: (1) saline, (2) sham Lliposomes, (3) free TQ (1 mg/kg), (4) free TQ (5 mg/kg), (5) free TQ (10 mg/kg), (6) Lip-TQ (1 mg/kg), 
(7) Lip-TQ (5 mg/kg), (8) Lip-TQ (10 mg/ $\mathrm{kg})$. The mice were observed for a period of 30 days after the $A$. baumannii infection.

\subsubsection{Determination of the Bacterial Load in Lung Tissues}

The effectiveness of TQ formulations was assessed by analyzing the bacterial load in lung tissues as described earlier [27]. Three mice from each group were sacrificed on day 5 post-treatment and equally weighed portions of the lung tissue were homogenized in sterile normal saline. After appropriate dilution in sterile normal saline, $100 \mu \mathrm{L}$ of the tissue homogenate were spread on nutrient agar plates. The plates were incubated at $37^{\circ} \mathrm{C}$ for $24 \mathrm{~h}$ to observe the growth of $A$. baumannii. The number of CFUs of $A$. baumannii in lung tissues was calculated using multiplication by the dilution factor.

\subsubsection{Determination of Leukocytes and Inflammation Markers}

On day 5 post-treatment, the total leukocyte and neutrophil counts were analyzed in the blood of mice using a hematology autoanalyzer [27]. The C-reactive protein (CRP) and procalcitonin (PCT) are commonly used inflammatory biomarkers to diagnose bacterial infections. The CRP and PCT levels were determined in blood samples using ELISA.

\subsubsection{Statistical Analyses}

The survival rate of the mice was analyzed using the Kaplan-Meier curve with the log-rank chi-squared test. The data of the bacterial load were analyzed by one-way ANOVA followed by the Bonferroni post-hoc test using the GraphPad Prism software, version 5.0 (La Jolla, CA, USA).

\section{Results}

\subsection{Antibiotic Susceptibility Pattern of A. baumannii}

The findings of the antibiotic disc susceptibility testing showed that drug-sensitive A. baumannii exhibited sensitivity to most of the antibiotics, including ampicillin (AP), ciprofloxacin (CIP), chloramphenicol (C), ceftriaxone (CRO), cefotaxime (CTX), penicillin $(\mathrm{PG})$, cefoxitin (FOX), cephalothin (KF), clindamycin (CD), norfloxacin (NOR), nitrofurantoin (NI), tobramycin (TN), ceftazidime (CAZ), imipenem (IMI) and piperacillin (PRL) (Figure 2A). A. baumannii (ATCC 19606) has been reported to exhibit resistance against various antibiotics [28]. Figure 2B shows that $A$. baumannii (ATCC 19606) was resistant to most of the antibiotics, including AP, C, CRO, CTX, cotrimoxazole (TS), PG, CD, FOX, NI, $\mathrm{KF}, \mathrm{CAZ}$ and aztreonam (ATM), whereas it exhibited susceptibility to CIP, nalidixic acid (NA), IMI and PRL (Figure 2B).

(A) Drug-sensitive A. baumannii
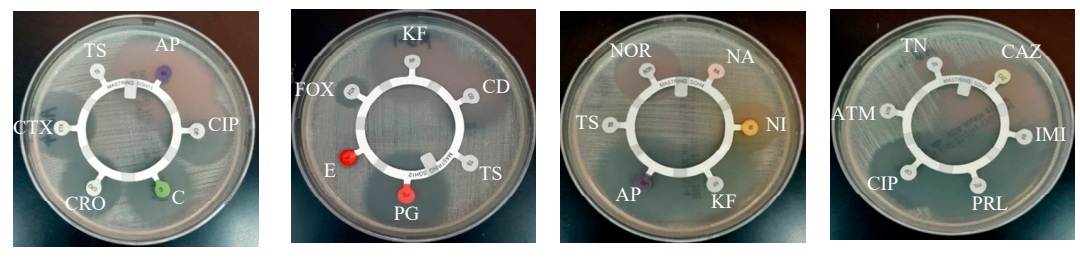

(B) Drug-resistant
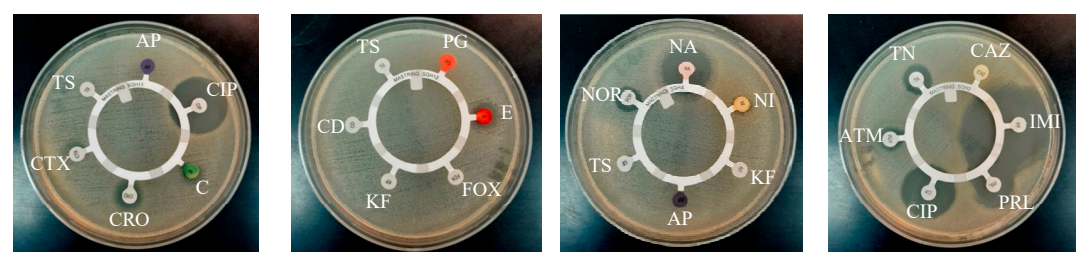

Figure 2. Antibiotic susceptibility screening of (A) drug-sensitive and (B) drug-resistant A. baumannii. 


\subsection{In Vitro Activity of $T Q$ against A. baumannii}

TQ demonstrated very strong activity against the drug-sensitive and drug-resistant A. baumannii (ATCC 19606) as well. The wells containing 25, 50 and $100 \mu \mathrm{g}$ of TQ exhibited 15-, 24- and 42-mm inhibition zones against drug-sensitive A. baumannii (Figure 3A), whereas the wells containing the same amounts of TQ exhibited 12-, 18- and 25-mm growth inhibition zones in the plates streaked with drug-resistant $A$. baumannii (Figure 3B). On the other hand, amoxicillin (AMX) demonstrated its strong activity against the drug-sensitive, but not against the drug-resistant $A$. baumannii (Figure 3C,D). The wells containing 25, 50 and $100 \mu \mathrm{g}$ of AMX exhibited 30-, 35- and 50-mm growth inhibition zones against drug-sensitive A. baumannii (Figure 3C), whereas drug-resistant A. baumannii (ATCC 19606) did not exhibit any susceptibility to AMX at the given concentrations (Figure 3D).

(A) Drug-sensitive A. baumannii

(B) Drug-resistant A. baumannii
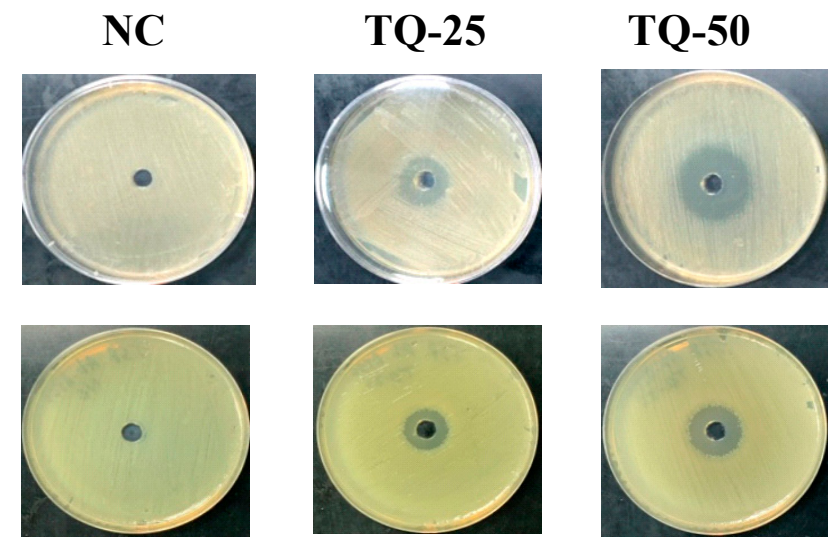

NC

(C) Drug-sensitive A. baumannii

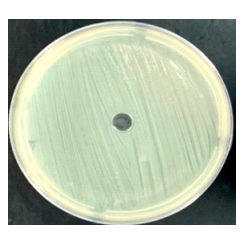

AMX-25

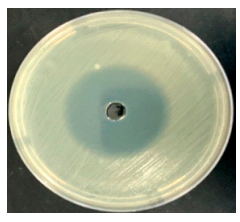

AMX-50

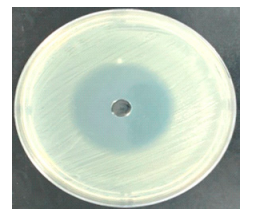

AMX-100

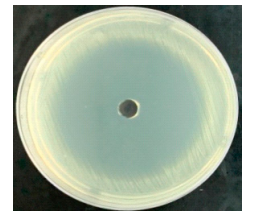

(D) Drug-resistant A. baumannii
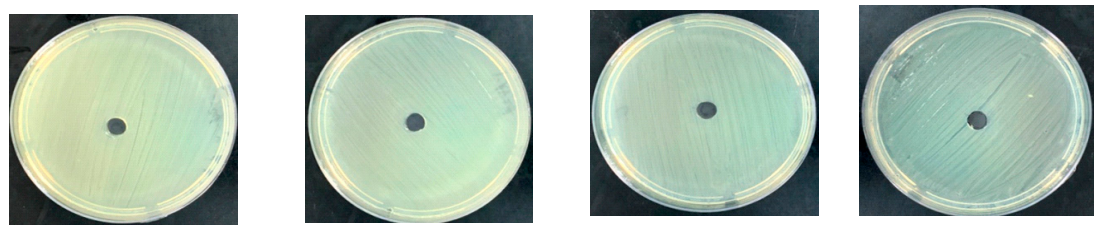

Figure 3. The activity of TQ or AMX against the drug-sensitive and drug-resistant A. baumannii. The activity of TQ (25, 50 and $100 \mu \mathrm{g} / \mathrm{mL}$ ) against the (A) drug-sensitive and (B) drug-resistant A. baumannii. The activity of AMX (25, 50 and $100 \mu \mathrm{g} / \mathrm{mL}$ ) against the (C) drug-sensitive and (D) drug-resistant A. baumannii. Negative controls (NC) contain 5\% DMSO.

The activity of TQ or AMX against the drug-sensitive and drug resistant A. baumannii was analyzed using microscopic analysis. The results revealed that TQ had strong activity against the drug-sensitive and drug-resistant $A$. baumannii, whereas AMX was effective against the drug-sensitive, but not the drug-resistant $A$. baumannii. TQ exhibited a dosedependent activity against the drug-sensitive and drug-resistant $A$. baumannii as well (Figure 4A,B). However, AMX was highly effective against drug-sensitive A. baumannii, but it was ineffective against drug-resistant $A$. baumannii (Figure 4C,D). 


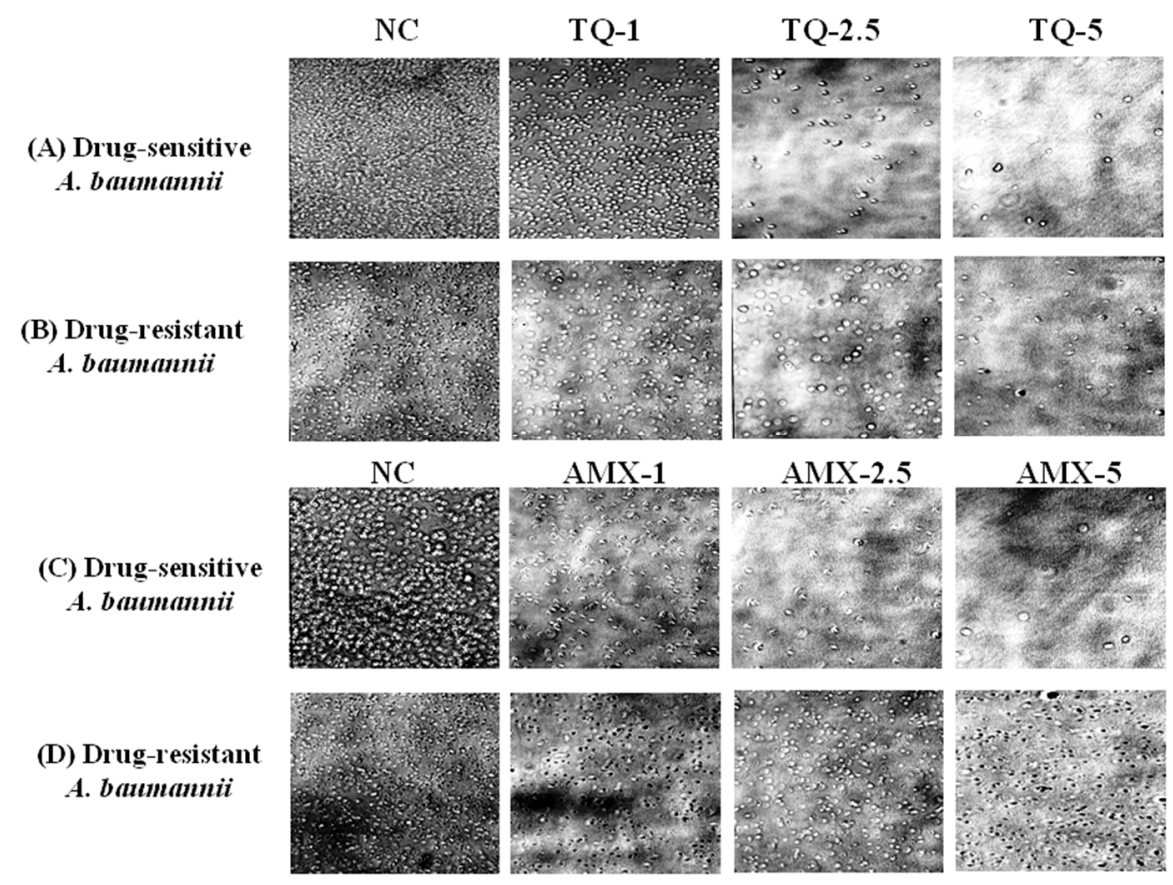

Figure 4. Microscopic analysis of the effect of TQ or AMX against the drug-sensitive and drugresistant $A$. baumannii. The activity of TQ $(1,2.5$ and $5 \mu \mathrm{g} / \mathrm{mL})$ against the $(\mathbf{A})$ drug-sensitive and (B) drug-resistant $A$. baumannii. The activity of $\operatorname{AMX}(1,2.5$ and $5 \mu \mathrm{g} / \mathrm{mL})$ against the (C) drugsensitive and (D) drug-resistant A. baumannii. Negative controls (NC) contain 5\% DMSO.

The MIC of TQ was determined by observing the turbidity of growth of A. baumannii. The MIC values for the drug-sensitive and drug-resistant $A$. baumannii were found to be 2 and $5 \mu \mathrm{g} / \mathrm{mL}$, respectively, whereas the MIC of AMX against drug-sensitive $A$. baumannii was found to be $1 \mu \mathrm{g} / \mathrm{mL}$.

\subsection{Activity of TQ against the Drug-Sensitive and Drug-Resistant A. baumannii According to} Time-Kill Studies

The bactericidal effect of TQ against the drug-sensitive and drug-resistant $A$. baumannii was studied using time-kill studies. The extent of $A$. baumannii killing was determined by a decrease in the number of CFUs at different timepoints. The findings of the present study demonstrated that there was time-dependent and dose-dependent activity of TQ against both drug-sensitive and drug-resistant $A$. baumannii (Figure 5A,B). TQ at all concentrations exhibited bactericidal effects against both drug-sensitive and drug-resistant $A$. baumannii at the 24-h timepoint. However, TQ at the concentrations of 2 and $4 \mu \mathrm{g} / \mathrm{mL}$ reduced the relative amount of drug-sensitive A. baumannii by $\geq 3 \log _{10} \mathrm{CFUs} / \mathrm{mL}$ (Figure $5 \mathrm{~A}$ ). $\mathrm{TQ}$, at the concentrations of 1 and $2 \mu \mathrm{g} / \mathrm{mL}$ decreased the bacterial count by $60 \%$ and $93 \%$, whereas TQ at the concentrations of 4 and $8 \mu \mathrm{g} / \mathrm{mL}$ killed $99.99 \%$ of A. baumannii (Figure 5A). On the contrary, drug-resistant $A$. baumannii exhibited less susceptibility to TQ, particularly at lower concentrations (Figure 5B). TQ at 1 and $2 \mu \mathrm{g} / \mathrm{mL}$ killed $44.6 \%$ and $75.7 \%$ of the original bacterial inoculum, whereas 4 and $8 \mu \mathrm{g} / \mathrm{mL}$ of TQ killed $99.4 \%$ and $>$ 99.99\% of drug-resistant $A$. baumannii (Figure $5 \mathrm{~B}$ ). 
A

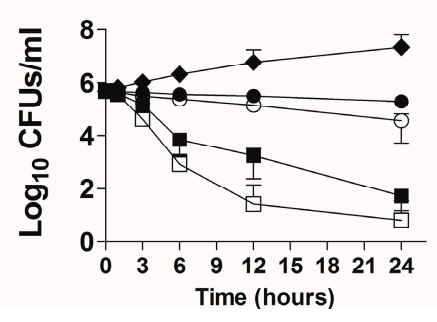

C

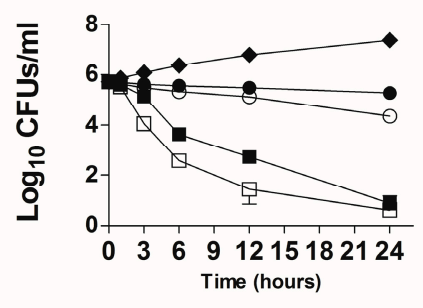

B

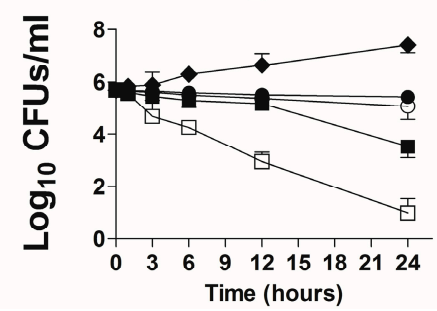

D

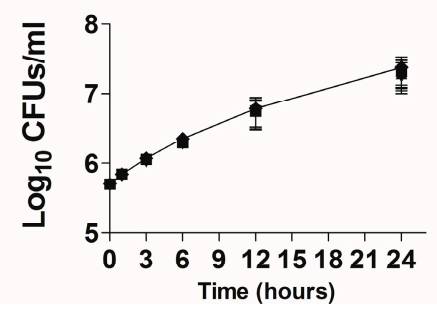

Figure 5. Time-kill curves of TQ or AMX at the doses of 1,2,4 and $8 \mu \mathrm{g} / \mathrm{mL}$ against the drug-sensitive and drug-resistant A. baumanni. Time-kill curves of TQ against the (A) drug-sensitive and (B) drugresistant A. baumannii. Time-kill curves of AMX against the (C) drug-sensitive and (D) drug-resistant A. baumannii. The data are represented as the means $\pm \mathrm{SD}$ of three independent experiments. Control $(\diamond), \mathrm{TQ}-1 \mu \mathrm{g} / \mathrm{mL}$ or $\mathrm{AMX}-1 \mu \mathrm{g} / \mathrm{mL}(\bullet), \mathrm{TQ}-2 \mu \mathrm{g} / \mathrm{mL}$ or $\mathrm{AMX} \longrightarrow 2 \mu \mathrm{g} / \mathrm{mL}(\bigcirc), \mathrm{TQ} \longrightarrow 4 \mu \mathrm{g} / \mathrm{mL}$ or $\mathrm{AMX}-4 \mu \mathrm{g} / \mathrm{mL}(\mathbf{\square}), \mathrm{TQ}-8 \mu \mathrm{g} / \mathrm{mL}$ or $\mathrm{AMX}-8 \mu \mathrm{g} / \mathrm{mL}(\square)$.

AMX demonstrated strong activity against drug-sensitive A. baumannii (Figure 5C). AMX at the concentrations of 2 and $4 \mu \mathrm{g} / \mathrm{mL}$ reduced the relative amount of drug-sensitive A. baumannii by $\geq 3 \log _{10} \mathrm{CFU} / \mathrm{mL}$ (Figure 5C). AMX at the concentrations of 1,2 and $4 \mu \mathrm{g} / \mathrm{mL}$ killed more than $99 \%$ of $A$. baumannii (Figure 5C). On the other hand, AMX was not effective against drug-resistant $A$. baumannii at the given concentrations (Figure 5D).

\subsection{Characterization of TQ Liposomes}

The PDI value indicates the homogeneity of nanoparticles between 0 and 1 . The PDI value of the TQ-loaded liposomes was found to be $0.212 \pm 0.006$. The lower PDI value of 0.212 indicates more uniformity of the liposomal TQ formulation. The zeta potential of thymoquinone liposomes was found to be $2.1 \mathrm{mV}$. The mean size of TQ liposomes was about $128 \mathrm{~nm}$ as determined by the TEM and DLS (Figure 6A,B). The percent EE of TQ was found to be about $90 \%$.

A

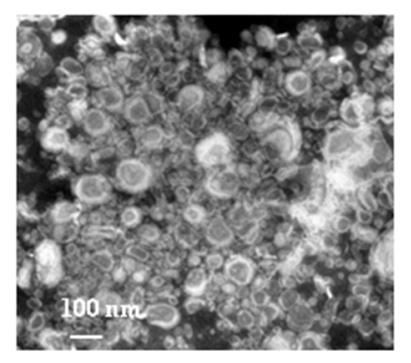

B

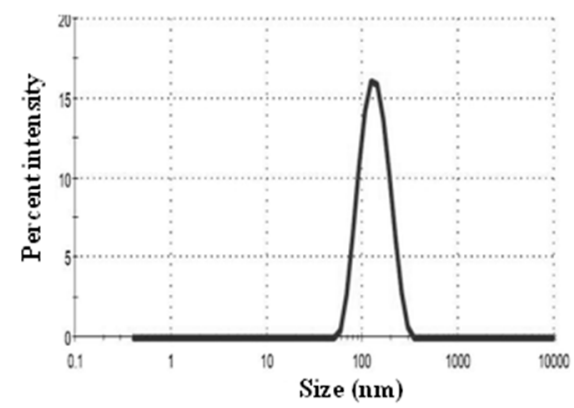

Figure 6. Characterization of liposomes. (A) A transmission electron microscopy (TEM) image of TQ liposomes, (B) size of TQ liposomes. 


\subsection{Stability of $T Q$-Encapsulated Liposomes and Release Kinetics of $T Q$}

The stability of Lip-TQ was determined in deionized water. As shown in Figure 7A, the release of TQ was found to be $3.76 \%$ and $4.2 \%$ at 12 - and 24 -h timepoints, respectively (Figure 7A). This small leakage of TQ from the liposomes suggests that the drug strongly interacted with the liposomes. The TQ-loaded liposomes were found to be quite stable in the presence of serum. The percent release of TQ from liposomes was found to be $16 \pm 0.53$ and $21 \pm 0.87$ after 12 and $24 \mathrm{~h}$ of incubation, respectively (Figure 7B).
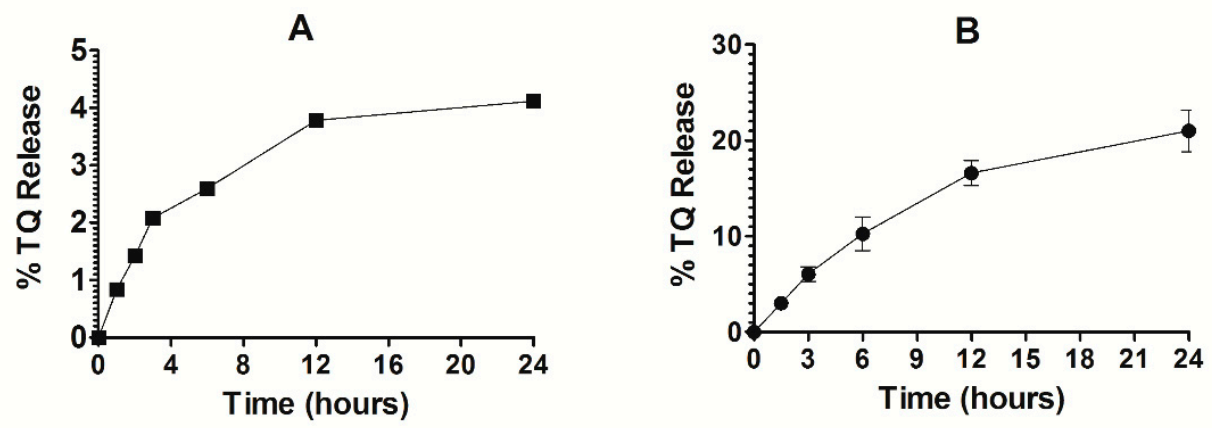

Figure 7. Stability and release kinetics of Lip-TQ. (A) Stability of Lip-TQ in deionized water, (B) Release kinetics of TQ from the liposomes into the serum.

\subsection{Administration of Free $T Q$ or Lip-TQ Did Not Induce any Significant Toxicity}

Free TQ or Lip-TQ at the doses of 1, 10, 20 and $40 \mathrm{mg} / \mathrm{kg}$ were administered to mice. The mice in the groups injected with the highest doses of free TQ or Lip-TQ $(40 \mathrm{mg} / \mathrm{kg})$ did not exhibit any mortality (Table 1). Moreover, no mortality was observed in other experimental groups as well. The administration of free TQ or Lip-TQ at a dose of $40 \mathrm{mg} / \mathrm{kg}$ did not induce any significant weight loss on day 8 as compared to day 1 (Table 1 ).

Table 1. Mortality and change in body weight in the mice injected with various doses of free TQ or Lip-TQ. The data are represented as the means \pm SD of three independent experiments.

\begin{tabular}{ccccc}
\hline Group & Mortality & \multicolumn{2}{c}{ Body Weight } \\
Day 5 & Day 1 & $28.8 \pm 2.2$ & $29.2 \pm 2.1$ \\
Vehicle control & $0 / 8$ & $28 \pm 2.4$ & $27.7 \pm 3.1$ & $28.2 \pm 3.3$ \\
Sham liposomes & $0 / 8$ & $27.4 \pm 3.0$ & $29.6 \pm 2.2$ & $30 \pm 2.0$ \\
Free TQ-1 mg/kg & $0 / 8$ & $29.6 \pm 1.8$ & $28.7 \pm 2.4$ & $28 \pm 3.4$ \\
Free TQ-10 mg/kg & $0 / 8$ & $28.8 \pm 2.5$ & $28.4 \pm 3.6$ & $27.8 \pm 3.6$ \\
Free TQ-20 mg/kg & $0 / 8$ & $28.6 \pm 2.4$ & $26.5 \pm 3.4$ & $26.4 \pm 3.1$ \\
Free TQ-40 mg/kg & $0 / 8$ & $28.2 \pm 2.2$ & $29.2 \pm 1.8$ & $27.7 \pm 1.5$ \\
Lip-TQ-1 mg/kg & $0 / 8$ & $26.6 \pm 1.7$ & $28.6 \pm 2.7$ & $27.6 \pm 2.5$ \\
Lip-TQ-10 mg/kg & $0 / 8$ & $28.5 \pm 3.8$ & $29 \pm 3.2$ & $28.2 \pm 4.0$ \\
Lip-TQ-20 mg/kg & $0 / 8$ & $29.4 \pm 2.6$ & $28.4 \pm 3.0$ & $27.8 \pm 3.8$ \\
Lip-TQ-40 mg/kg & $0 / 8$ & $29 \pm 3.5$ & & \\
\hline
\end{tabular}

\subsection{Administration of Free TQ or Lip-TQ Did Not Induce any Remarkable Changes in} Hematological Parameters

The administration of free TQ or Lip-TQ did not induce significant changes in hematological parameters except the erythrocyte count in the mice treated with free TQ at a dose of $40 \mathrm{mg} / \mathrm{kg}$ (Table 2). The erythrocyte counts were found to be $(8.44 \pm 1.1) \times 10^{6}$ in the normal control mice as compared to $(6.1 \pm 0.76) \times 10^{6}$ per $\mathrm{mm}^{3}$ in the blood of the mice injected with free TQ at a dose of $40 \mathrm{mg} / \mathrm{kg}(p<0.05)$. 
Table 2. Hematological parameters of the mice injected with various doses of free TQ or Lip-TQ.

\begin{tabular}{|c|c|c|c|}
\hline Group & Erythrocytes $/ \mathrm{mm}^{3} \times\left(10^{6}\right)$ & Leukocytes $/ \mathrm{mm}^{3} \times\left(10^{3}\right)$ & Platelets $/ \mathrm{mm}^{3} \times\left(10^{5}\right)$ \\
\hline Vehicle control & $8.44 \pm 1.1$ & $6.6 \pm 2.23$ & $4.64 \pm 1.12$ \\
\hline Sham liposomes & $8.28 \pm 1.4$ & $6.8 \pm 2.52$ & $4.46 \pm 2.04$ \\
\hline Free TQ-1 mg/kg & $8.12 \pm 0.92$ & $7.1 \pm 2.54$ & $4.48 \pm 1.24$ \\
\hline Free TQ-10 mg/kg & $7.88 \pm 1.6$ & $6.8 \pm 1.88$ & $4.59 \pm 2.10$ \\
\hline Free $\mathrm{TQ}-20 \mathrm{mg} / \mathrm{kg}$ & $7.22 \pm 0.96$ & $6.6 \pm 1.92$ & $4.2 \pm 1.66$ \\
\hline Free TQ-40 mg/kg & $6.1 \pm 0.76^{*}$ & $5.7 \pm 1.75$ & $3.8 \pm 1.62$ \\
\hline Lip-TQ_-1 mg/kg & $8.76 \pm 1.5$ & $7.22 \pm 1.72$ & $4.88 \pm 1.78$ \\
\hline Lip-TQ-10 mg/kg & $8.26 \pm 1.8$ & $6.94 \pm 1.56$ & $4.06 \pm 1.63$ \\
\hline Lip-TQ-20 mg/kg & $7.52 \pm 0.92$ & $6.2 \pm 2.8$ & $4.1 \pm 1.92$ \\
\hline Lip-TQ—40 mg/kg & $7.33 \pm 1.2$ & $6.24 \pm 2.4$ & $4.1 \pm 1.66$ \\
\hline
\end{tabular}

${ }^{*} p<0.05$ as compared to vehicle control.

\subsection{Effect of Free TQ or Lip-TQ on Liver and Kidney Function Parameters}

The effect of free TQ or Lip-TQ on liver toxicity was determined by analyzing the levels of AST and ALT, whereas the kidney function was evaluated by the changes in the levels of blood urea nitrogen (BUN) and creatinine (Table 3). The administration of free TQ at a dose of $40 \mathrm{mg} / \mathrm{kg}$ increased the level of AST to $69 \pm 7.6 \mathrm{IU} / \mathrm{L}$, which was significantly higher as compared to $24 \pm 4.6 \mathrm{IU} / \mathrm{L}$ in the vehicle control $(p<0.01)$. The mice treated with Lip-TQ $(40 \mathrm{mg} / \mathrm{kg})$ exhibited a significant elevation in the AST level to $47.2 \pm 7.8(p<0.05)$. Similarly to the AST level, the level of ALT was also significantly increased in the mice treated with free TQ $(p<0.05)$.

Table 3. Effect of free TQ or Lip-TQ on hepatic and renal toxicity.

\begin{tabular}{ccccc}
\hline Group & AST (IU/L) & ALT (IU/L) & BUN (mg/dL) & Creatinine (mg/dL) \\
\hline Vehicle control & $24 \pm 4.6$ & $32 \pm 5.8$ & $18 \pm 2.8$ & $0.46 \pm 0.08$ \\
Sham liposomes & $26 \pm 3.2$ & $27.8 \pm 6.2$ & $22 \pm 2.2$ & $0.52 \pm 0.10$ \\
Free TQ-1 mg/kg & $32 \pm 2.5$ & $28.4 \pm 5.2$ & $25 \pm 2.8$ & $0.48 \pm 0.12$ \\
Free TQ-10 mg/kg & $36 \pm 6.6$ & $27.8 \pm 6.2$ & $28 \pm 5.1$ & $0.55 \pm 0.11$ \\
Free TQ-20 mg/kg & $48 \pm 11.4$ & $32.6 \pm 6.0$ & $32.3 \pm 4.8$ & $0.64 \pm 0.24$ \\
Free TQ-40 mg/kg & $69 \pm 7.6^{* *}$ & $48.8 \pm 5.2^{*}$ & $21 \pm 4.4$ & $0.66 \pm 0.16$ \\
Lip-TQ-1 mg/kg & $22 \pm 2.7$ & $26.2 \pm 5.4$ & $22 \pm 3.8$ & $0.38 \pm 0.07$ \\
Lip-TQ-10 mg/kg & $27.4 \pm 4.2$ & $29.4 \pm 4.8$ & $23.6 \pm 4.0$ & $0.47 \pm 0.11$ \\
Lip-TQ-20 mg/kg & $36.6 \pm 7.4$ & $34.2 \pm 7.6$ & $25.8 \pm 3.8$ & $0.49 \pm 0.09$ \\
Lip-TQ-40 mg/kg & $47.2 \pm 7.8^{*}$ & $38.2 \pm 7.3$ & $0.58 \pm 0.14$ \\
\hline
\end{tabular}

${ }^{*} p<0.05,{ }^{* *} p<0.01$ as compared to vehicle control.

The level of BUN significantly increased from $18 \pm 2.8$ to $34.5 \pm 6.6 \mathrm{mg} / \mathrm{dL}$ in the mice treated with free TQ at a dose of $40 \mathrm{mg} / \mathrm{kg}(p<0.05)$, whereas Lip-TQ at a dose of $40 \mathrm{mg} / \mathrm{kg}$ did not induce any significant elevation in the BUN level (Table 3). Creatinine, the second important parameter of kidney function, did not induce any significant increase in the mice treated with free TQ or Lip-TQ at a dose of $40 \mathrm{mg} / \mathrm{kg}$ (Table 3).

\subsection{Susceptibility of Mice to Intravenous Infection by A. baumannii}

The susceptibility of mice to A. baumannii was examined in order to choose an appropriate bacterial inoculum for infection. The mice infected with the largest bacterial inoculum $\left(1 \times 10^{8} \mathrm{CFUs}\right)$ died within four days after the $A$. baumannii infection, whereas all the mice infected with $5 \times 10^{7} \mathrm{CFUs}$ died by day 10 post-infection (data not shown). The mice infected with $1 \times 10^{7}, 5 \times 10^{6}, 1 \times 10^{6}$ CFUs exhibited a $30 \%, 80 \%$ and $90 \%$ survival rate on day 10 post-infection, respectively. Based on the survival results, we selected $1 \times 10^{7} \mathrm{CFUs}$ of $A$. baumannii to infect mice in further experiments. 


\subsection{Treatment with Lipsomal-TQ-Protected Mice against the Systemic Infection of Drug-Sensitive A. baumannii}

Mice in the saline-treated group or the sham liposome-treated group died within 14 days post-infection with drug-sensitive $A$. baumannii (Figure $8 \mathrm{~A}$ ). The mean survival time (MST) in the saline-treated group was 7.5 days, whereas the mice treated with free TQ $(1 \mathrm{mg} / \mathrm{kg})$ had the MST of 11.5 days $(p=0.0271)$. The A. baumannii-infected mice treated with Lip-TQ $(1 \mathrm{mg} / \mathrm{kg})$ had the MST of 15 days as compared to that of eight days in the mice treated with sham liposomes $(p=0.009)$. The A. baumannii-infected mice treated with Lip-TQ at a dose of $5 \mathrm{mg} / \mathrm{kg}$ exhibited a $60 \%$ survival rate, whereas the mice treated with free TQ at the same dose had a $20 \%$ survival rate on day 30 post-treatment (Figure $8 \mathrm{~A}$ ). The mice in the group treated with Lip-TQ $(10 \mathrm{mg} / \mathrm{kg})$ had the highest survival rate of $90 \%$ in comparison to a $40 \%$ survival rate of the group of mice treated with free TQ at the same dose $(p=0.0195)$. The efficacy of treatment was determined by evaluating the bacterial burden in lung tissues (Figure 8B). The mice in the saline-treated group had the bacterial load of $884,628 \pm 189,985$ CFUs/gm in the lung tissue, whereas free TQ $(5 \mathrm{mg} / \mathrm{kg}$ and $10 \mathrm{mg} / \mathrm{kg}$ ) reduced the bacterial load to $296,945 \pm 50,277$ and 148,027 $\pm 39,521 \mathrm{CFU} / \mathrm{g}$, respectively $(p<0.001)$. Treatment with Lip-TQ $(5 \mathrm{mg} / \mathrm{kg}$ and $10 \mathrm{mg} / \mathrm{kg})$ further decreased the bacterial load to $57,749 \pm 15,126$ and $10,475 \pm 6060 \mathrm{CFU} / \mathrm{g}$ that was significantly lower as compared to the bacterial load of $905,327 \pm 180,579$ in the sham-Lip-treated mice $(p<0.001)$. On day 30 post-infection, the surviving mice were sacrificed to assess the residual bacterial infection in lung tissues. The results demonstrated that all the surviving mice were found to be free of the A. baumannii infection.

AMX demonstrated a potent antibacterial activity against drug-sensitive A. baumannii in a mouse model (Figure $8 \mathrm{C}$ ). The A. baumannii-infected mice treated with AMX $(10 \mathrm{mg} / \mathrm{kg}$ ) exhibited a $100 \%$ survival rate on day 30 post-infection (Figure $8 \mathrm{C}$ ), which is highly significant as compared to the saline-treated mice $(p<0.001)$. The mice treated with AMX at a dose of $5 \mathrm{mg} / \mathrm{kg}$ had a $70 \%$ survival rate $(p=0.0023)$. The severity of the infection was analyzed by assessing the bacterial load in lung tissues (Figure 8D). The mice in the saline-treated group had a bacterial load of 751,295 $\pm 150,582 \mathrm{CFU} / \mathrm{g}$ in lung tissues (Figure 8D), whereas, the treatment with AMX $(5 \mathrm{mg} / \mathrm{kg}$ and $10 \mathrm{mg} / \mathrm{kg}$ ) reduced the bacterial load to $41,749 \pm 7987$ and $3708 \pm 2746 \mathrm{CFU} / \mathrm{g}$, respectively $(p<0.001)$. AMX treatment at a dose of $1 \mathrm{mg} / \mathrm{kg}$ reduced the bacterial load to 372,270 $\pm 78,934 \mathrm{CFU} / \mathrm{g}$ of the lung tissue, which was significantly lower as compared to the bacterial load in lung tissues of the saline-treated mice $(p<0.01)$. On day 30 post-infection, the surviving mice were sacrificed to monitor the residual bacterial infection in lung tissues. The results demonstrated that all the mice were found to be free of the A. baumannii infection.

\subsection{Lip-TQ, but Not AMX, Was Effective in the Treatment of the Systemic Infection of Drug-Resistant A. baumannii}

The mice in the saline-treated or sham liposome-treated groups died by day 12 postinfection with drug-resistant $A$. baumannii (Figure 9A). Treatment with Lip-TQ (10 mg/kg) imparted the highest survival rate of $70 \%$, whereas the mice treated with free TQ at the same dose had only a $20 \%$ survival rate $(p=0.0298)$. In a similar way, the mice in the Lip-TQ ( $5 \mathrm{mg} / \mathrm{kg}$ )-treated group had a 30\% survival rate. Contrary to this, the mice treated with free TQ at the same dose died within 30 days post-infection $(p=0.0277)$. The severity of the infection was also analyzed by determining the bacterial load in lung tissues. The number of CFUs of A. baumannii was found to be $934,628 \pm 208,329$ per gram of the lung tissue in the saline-treated group (Figure 9B). The mice treated with Lip-TQ $(10 \mathrm{mg} / \mathrm{kg})$ had the lowest bacterial load of $47,061 \pm 12,412$ CFUs in lung tissues in comparison to $189,027 \pm 45,542$ CFUs in the lungs of the mice treated with the same dose of free TQ (Figure 9B). The bacterial load was found to be $108,883 \pm 33,421 \mathrm{CFU} / \mathrm{g}$ of the lung tissue of the mice treated with Lip-TQ (5 mg/ $\mathrm{kg}$ ) as compared to 390,279 $\pm 16,765$ CFUs in the mice treated with free TQ at the same dose. Lip-TQ was most effective at a dose of $10 \mathrm{mg} / \mathrm{kg}$ that reduced the bacterial load to 20,394 $\pm 8,105 \mathrm{CFU} / \mathrm{g}$ of the lung tissue $(p<0.001)$. 
A

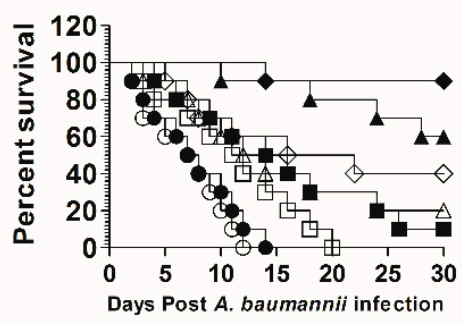

C

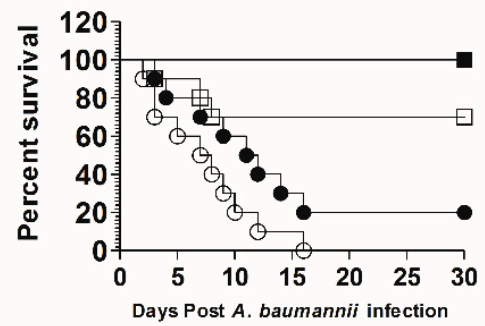

B

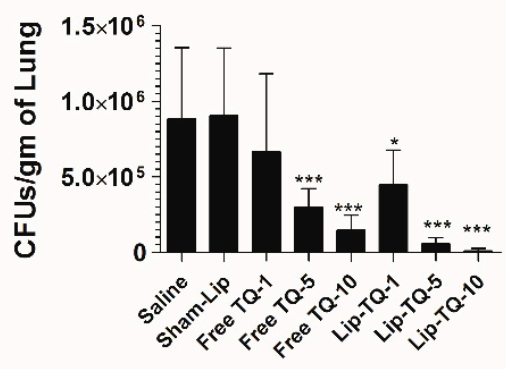

D

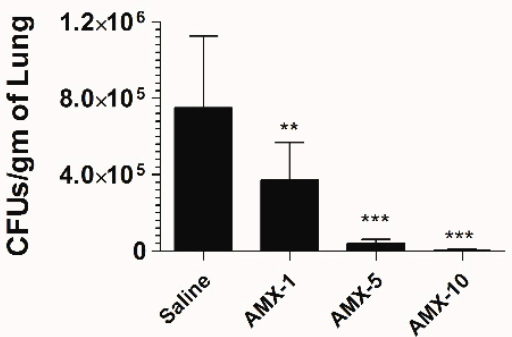

Figure 8. Lip-TQ or AMX effectively eliminated the drug-sensitive A. baumannii infection in a murine model. (A) Each mouse was infected with $1 \times 10^{7}$ CFUs of A. baumannii through an intravenous dose. After $12 \mathrm{~h}$ of the infection, the mice were treated with 1,5 and $10 \mathrm{mg} / \mathrm{kg}$ of free TQ and Lip-TQ for seven consecutive days. The mice were monitored for 30 days for the survival. Saline $(\bigcirc)$, sham-Lip (•), free TQ-1 mg/kg $(\square)$, free TQ—5 mg/kg $(\triangle)$, free TQ—10 mg/kg $(\diamond)$, Lip-

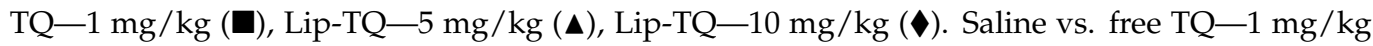
$(p=0.0271)$, sham-Lip vs. Lip-TQ-1 mg/kg ( $p=0.009)$, free TQ-5 mg/kg vs. Lip-TQ-5 mg/kg $(p=0.0195)$, free TQ-10 mg/kg vs. Lip-TQ-10 mg/kg ( $p=0.0195)$. (B) The bacterial load (CFUs) was determined as described in the methodology section. The data are represented as the means \pm SD of three independent experiments. ${ }^{*} p<0.05,{ }^{* * *} p<0.001$. (C) The mice infected with drug-sensitive A. baumannii were treated with $\operatorname{AMX}(1,5$ and $10 \mathrm{mg} / \mathrm{kg})$ for seven days and their survival rate was observed on day 30 after the infection. Saline $(\bigcirc), A M X-1 \mathrm{mg} / \mathrm{kg}(\bullet), \mathrm{AMX}-5 \mathrm{mg} / \mathrm{kg}(\square)$, $\mathrm{AMX}-10 \mathrm{mg} / \mathrm{kg}(\boldsymbol{\square})$. Saline vs. AMX $-5 \mathrm{mg} / \mathrm{kg}(p=0.0023)$, saline vs. AMX $-10 \mathrm{mg} / \mathrm{kg}(p<0.001)$. (D) The bacterial load (CFUs) was determined as described in the methodology section. The data are represented as the means $\pm \mathrm{SD}$ of three independent experiments. ${ }^{* *} p<0.01,{ }^{* * *} p<0.001$.

A. baumannii (ATCC 19606) did not respond to AMX treatment in a mouse model. The mean survival time (MST) of the mice in the group treated with AMX at a dose of $10 \mathrm{mg} / \mathrm{kg}$ was 8.5 days as compared to that of six days in the saline-treated mice (Figure $9 \mathrm{C})(p>0.05)$. Similarly, the bacterial load was found to be very high in lung tissues of the mice treated with AMX at the doses of 1, 5 and $10 \mathrm{mg} / \mathrm{kg}$ (Figure 9D). The bacterial load was found to be $922,051 \pm 57,960$ per gram of the lung tissue in the saline-treated group (Figure 9D), whereas the bacterial load in lung tissues of the mice treated with AMX at the highest dose of $10 \mathrm{mg} / \mathrm{kg}$ was found to be $894,903 \pm 168,494(p>0.05)$. This shows that AMX treatment did not reduce the severity of the A. baumannii infection in the treated mice. 
A

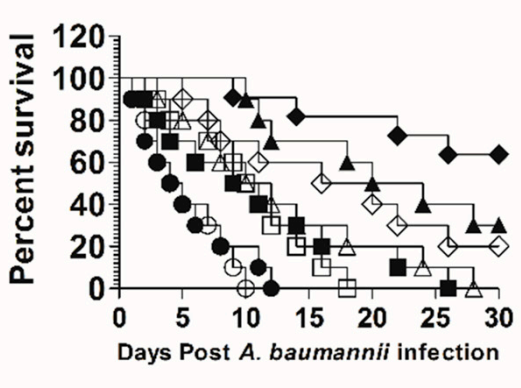

C

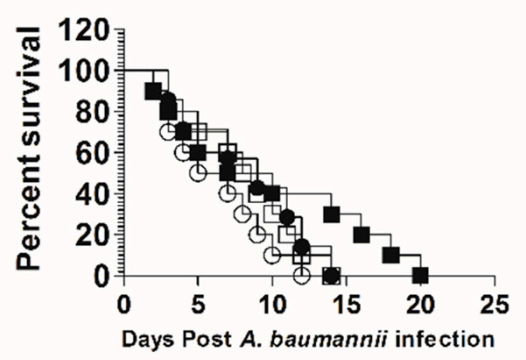

B

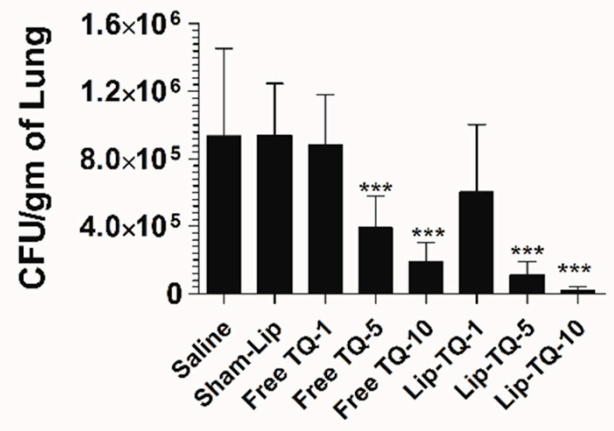

D

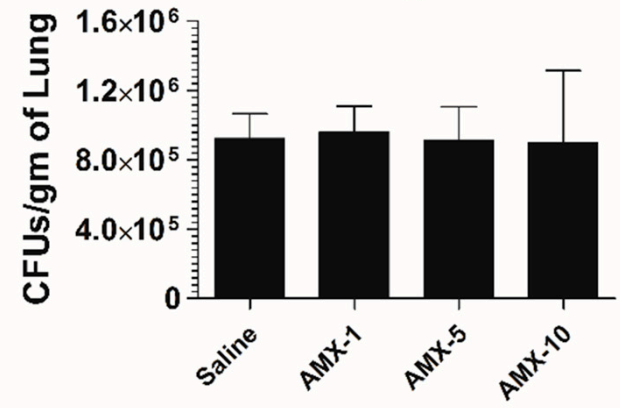

Figure 9. Treatment with Lip-TQ, not with $\mathrm{AMX}$, was effective against the drug-resistant A. baumannii infection in a murine model. (A) Each mouse was infected with $1 \times 10^{7} \mathrm{CFUs}$ of drug-resistant $A$. baumannii and treated with 1,5 and $10 \mathrm{mg} / \mathrm{kg}$ of free TQ or Lip-TQ for seven days as described in the methodology section. The survival rate of the mice was monitored for 30 days. Saline $(\bigcirc)$, sham-Lip (•), free TQ $-1 \mathrm{mg} / \mathrm{kg}(\square)$, free TQ—5 mg/kg $(\triangle)$, free TQ—10 mg/kg $(\diamond), \mathrm{Lip}-\mathrm{TQ}-1 \mathrm{mg} / \mathrm{kg}(\boldsymbol{\square}), \mathrm{Lip}-\mathrm{TQ}-5 \mathrm{mg} / \mathrm{kg}(\boldsymbol{\Delta}), \mathrm{Lip}-\mathrm{TQ}-10 \mathrm{mg} / \mathrm{kg}(\boldsymbol{\vee})$. Saline vs. free TQ-1 mg/kg $(p=0.0051)$, sham-Lip vs. Lip-TQ—1 mg/kg ( $p=0.0368)$, free TQ—5 mg/ $\mathrm{kg}$ vs. Lip-TQ—5 mg/ $\mathrm{kg}(p=0.0272)$, free TQ—10 mg/kg vs. Lip-TQ $-10 \mathrm{mg} / \mathrm{kg}(p=0.0295)$. (B) Three mice from each group were sacrificed on day 5 after thetreatment and equally weighed portions of the lung tissue were homogenized to determine the bacterial load. The data are represented as the means \pm SD of three independent experiments. ${ }^{* * *} p<0.001$. (C) The mice infected with drug-resistant A. baumannii were treated with AMX (1,5 and $10 \mathrm{mg} / \mathrm{kg}$ ) for seven days and their survival rate was observed on day 30 post-infection.

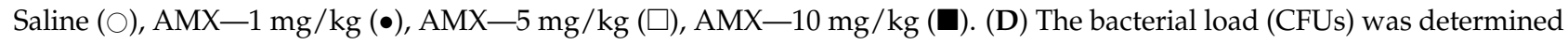
as described in the methodology section. The data are represented as the means \pm SD of three independent experiments.

\subsection{Treatment with Lip-TQ, Not AMX, Alleviated the Parameters of Total Leukocytes and Neutrophils in the Mice Infected with Drug-Resistant A. baumannii}

The counts of total leukocytes and neutrophils were significantly increased in the $A$. baumannii-infected mice. The leukocyte count increased from $6277 \pm 959$ to $17,766 \pm 1533$ per $\mathrm{mm}^{3}$ in the blood of A. baumannii infected mice (Figure 10A) $(p<0.001)$. Since TQ at a dose of $10 \mathrm{mg} / \mathrm{kg}$ alleviated A. baumannii infection, the mice treated with free TQ or Lip-TQ at a dose of $10 \mathrm{mg} / \mathrm{kg}$ had significantly reduced leukocyte numbers on day 7 post-treatment ( $p<0.001)$. A. baumannii infected mice treated with Lip-TQ $(10 \mathrm{mg} / \mathrm{kg})$ had $7665 \pm 1504$ per $\mathrm{mm}^{3}$ as compared to the leukocyte count of $17,766 \pm 1533$ per $\mathrm{mm}^{3}$ in the blood of untreated mice $(p<0.001)$. Treatment with free TQ at a dose of $10 \mathrm{mg} / \mathrm{kg}$ significantly reduced the leukocyte count to 11,664 per $\mathrm{mm}^{3}(p<0.01)$. A. baumannii-infected mice treated with AMX exhibited significantly higher levels of leukocytes as the AMX treatment at the given doses was ineffective to eliminate the A. baumannii infection (Figure 10B). The leukocyte count increased from $6014 \pm 920$ to $18,100 \pm 1400$ per $\mathrm{mm}^{3}$ in the blood of the A. baumannii-infected mice (Figure 10B). Treatment with AMX at a dose of $10 \mathrm{mg} / \mathrm{kg}$ reduced the leukocyte count to $15,652 \pm 1459$ per $\mathrm{mm}^{3}$, which was insignificantly reduced as compared to the leukocyte count in the saline-treated mice $(p>0.05)$. 
A

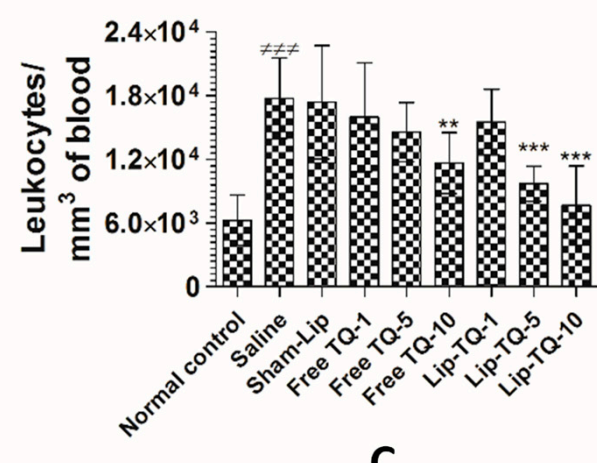

C

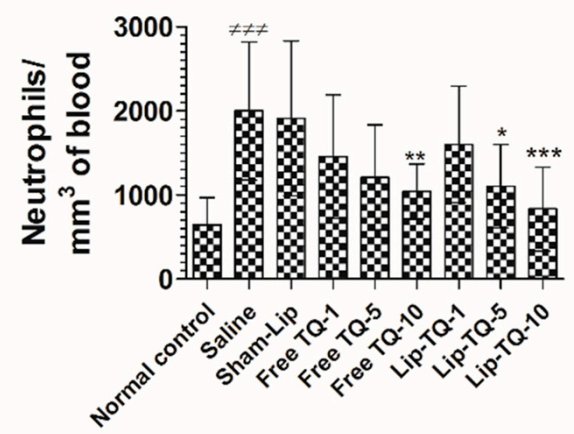

B
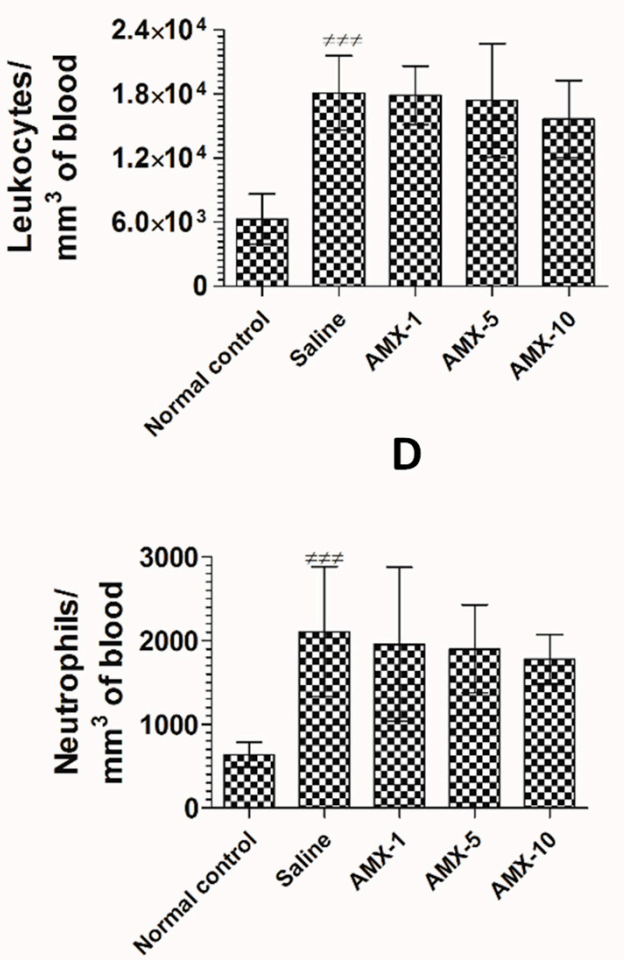

Figure 10. Treatment with Lip-TQ, but not with AMX, alleviated the parameters of total leukocytes and neutrophils in the mice infected with drug-resistant $A$. baumannii. On day 5 post-treatment, the blood was sampled from three mice and the leukocyte and neutrophil counts were analyzed. (A) Leukocytes in the free TQ- or Lip-TQ-treated mice, (B) leukocytes in the AMX-treated mice, (C) neutrophils in the free TQ- or Lip-TQ-treated mice, (D) neutrophils in the AMX-treated mice. The data are represented as the means $\pm \mathrm{SD}$ of three independent experiments. $\neq \neq \neq p<0.001$. Normal control vs. saline-treated mice, ${ }^{*} p<0.05,{ }^{* *} p<0.001,{ }^{* * *} p<0.001$. Saline vs. free TQ or Lip-TQ treatment groups.

Neutrophils are important cells of the innate immune response and their numbers increase manifold in acute bacterial infections. The findings of the present study showed that the neutrophil count increased from $645 \pm 130$ to $2001 \pm 330$ per $\mathrm{mm}^{3}$ of blood in the A. baumannii-infected mice (Figure 10C) $(p<0.001)$. Administration of free TQ or Lip-TQ $(10 \mathrm{mg} / \mathrm{kg})$ decreased the neutrophil count in the infected mice $(p<0.01$ and $p<0.001$, respectively). Noteworthy, the A. baumannii-infected mice treated with Lip-TQ ( $5 \mathrm{mg} / \mathrm{kg}$ ) had a significantly lower neutrophil count compared to the sham-Lip-treated mice $(p<0.05)$. Similarly to the leukocyte count, the AMX-treated mice had a remarkably increased neutrophil count (Figure 10D). The neutrophil count increased from $636 \pm 60$ to $2107 \pm 312$ per $\mathrm{mm}^{3}$ of blood in the A. baumannii-infected mice $(p<0.001)$. Treatment with AMX at a dose of $10 \mathrm{mg} / \mathrm{kg}$ reduced the neutrophil count to $1780 \pm 117$ per $\mathrm{mm}^{3}$ which was insignificantly lower as compared to the neutrophil count in the saline-treated mice $(p>0.05)$.

3.13. Treatment with Lip-TQ, Not AMX, Alleviated the Parameters of Inflammation Markers in the Mice Infected with Drug-Resistant A. baumannii

The C-reactive protein (CRP) and procalcitonin (PCT) are common blood biomarkers in bacterial infections. The results of the present study demonstrated that the CRP level was considerably increased in the blood of the A. baumannii-infected mice (Figure 11A). The level of the CRP increased to $31.33 \pm 4 \mu \mathrm{g} / \mathrm{mL}$, which was significantly higher as compared to the CRP value of $3 \pm 1.8 \mu \mathrm{g} / \mathrm{mL}$ in the uninfected mice $(p<0.001)$. Treatment at a dose of $10 \mathrm{mg} / \mathrm{kg}$ of free TQ significantly decreased the CRP level to $10.33 \pm 3.5$ $(p<0.001)$, whereas treatment with Lip-TQ at the same dose reduced the CRP level to 
$6.667 \pm 2(p<0.001)$. On the other hand, the drug-resistant A. baumannii-infected mice treated with AMX did not exhibit any significant change in the CRP level (Figure 11B). The mice in the group treated with the highest dose of AMX $(10 \mathrm{mg} / \mathrm{kg})$ had $27.67 \pm 4.7$ $\mu \mathrm{g} / \mathrm{mL}$ of the CRP as compared to that of $30.33 \pm 5.5 \mu \mathrm{g} / \mathrm{mL}$ in the saline-treated mice $(p>0.05)$.

A

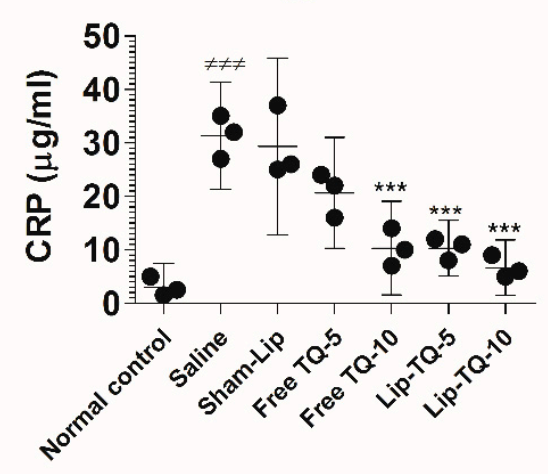

C

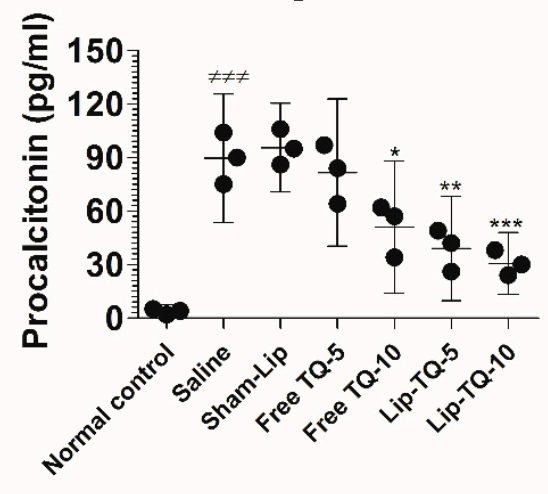

B

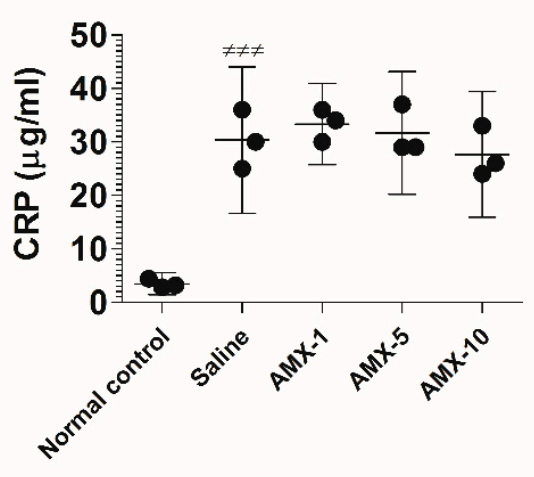

D

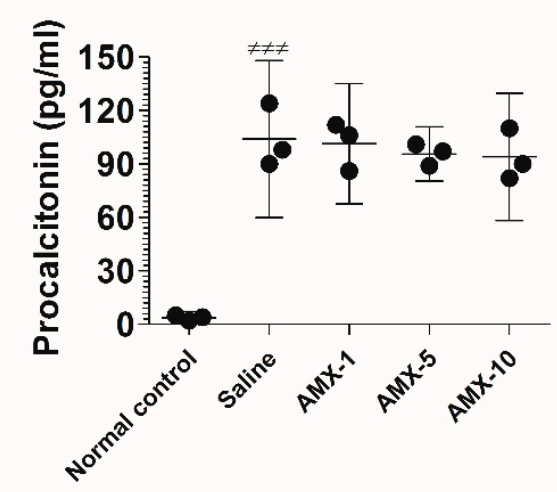

Figure 11. Treatment with Lip-TQ, but not with $A M X$, alleviated the parameters of the CRP and PCT in the mice infected with drug-resistant A. baumannii. On day 5 post-treatment, the blood was sampled from three mice and the levels of the CRP and PCT were analyzed. (A) The CRP in the free TQ- or Lip-TQ-treated mice, (B) the CRP in the AMX-treated mice, (C) PCT in the free TQ- or Lip-TQ-treated mice, (D) PCT in the AMX-treated mice. The data are represented as the means \pm SD of three independent experiments. ${ }^{\neq \neq \neq} p<0.001$. Normal control vs. saline-treated mice, ${ }^{*} p<0.05$, ${ }^{* *} p<0.001,{ }^{* * *} p<0.001$. Saline vs. free TQ or Lip-TQ treatment groups.

Similarly to the CRP level, the level of PCT was elevated to $89.67 \pm 14.5 \mathrm{pg} / \mathrm{mL}$ in the A. baumannii-infected mice (Figure 11C), which was significantly higher as compared to $3.6 \pm 1.5 \mathrm{pg} / \mathrm{mL}$ in the normal control mice $(p<0.001)$. Free TQ at a dose of $10 \mathrm{mg} / \mathrm{kg}$ reduced the PCT level to $51 \pm 14.93 \mathrm{pg} / \mathrm{mL}(p<0.05)$. Importantly, the treatment with Lip-TQ (5 and $10 \mathrm{mg} / \mathrm{kg}$ ) substantially reduced PCT levels to $39 \pm 11.79 \mathrm{pg} / \mathrm{mL}$ and $30.67 \pm 7 \mathrm{pg} / \mathrm{mL}$, respectively ( $p<0.01$ and $p<0.001$, respectively). Similarly to its effect on the CRP level, AMX treatment could not alleviate the level of PCT in the A. baumanniiinfected mice (Figure 11D). The level of PCT was elevated to $104 \pm 17.78 \mathrm{pg} / \mathrm{mL}$ in the saline-treated mice as compared to $3.67 \pm 1.2 \mathrm{pg} / \mathrm{mL}$ in the blood of the normal control mice $(p<0.001)$. Treatment of mice with the highest dose of AMX $(10 \mathrm{mg} / \mathrm{kg})$ reduced the PCT level from $104 \pm 17.78 \mathrm{pg} / \mathrm{mL}$ to $94 \pm 14.4 \mathrm{pg} / \mathrm{mL}$, which was statistically insignificant $(p>0.05)$. 


\section{Discussion}

In recent years, $A$. baumannii has been posing a serious threat to the human population and there is a dire need to find new antibiotics for the treatment [29]. Recently, there has been a huge increase in the emergence of drug-resistant isolates of $A$. baumannii. Multiple antibiotics, including aminopenicillins and first- and second-generation cephalosporins have been shown to be ineffective in the treatment of the drug-resistant A. baumannii infection. They have adopted various drug resistance mechanisms, including increased expression of multidrug efflux pumps, target gene mutation, enzymatic inactivation of antibiotics and changes in outer membrane permeability [30]. Keeping in mind an increased emergence of drug-resistant $A$. baumannii, it is important to find an effective and safe antibacterial agent to combat them. The findings of the present study demonstrated that treatment with Lip-TQ was effective against both drug-sensitive and drug-resistant A. baumannii.

In the present work, we included both drug-sensitive and drug-resistant $A$. baumannii. A. baumannii (ATCC 19606) has exhibited resistance to multiple antibiotics, including ampicillin, amoxicillin, chloramphenicol, cefotaxime, cotrimoxazole, penicillin, erythromycin, clindamycin, cephalothin, ceftazidime and aztreonam. Because of the broad-spectrum antimicrobial activity of TQ, we attempted to analyze the activity of TQ against $A$. baumannii. Interestingly, TQ exhibited antibacterial activity against both drug-sensitive and drug-resistant $A$. baumannii. The in vitro activity of TQ against $A$. baumannii was demonstrated by the agar well diffusion, dilution and time-kill assays. However, the MIC of TQ $(5 \mu \mathrm{g} / \mathrm{mL})$ was found to be higher against drug-resistant $A$. baumannii as compared to MIC of $2 \mu \mathrm{g} / \mathrm{mL}$ against drug-sensitive $A$. baumannii. The results of the time-kill assay demonstrated that TQ killed not only drug-sensitive A. baumannii, but also killed more than $99 \%$ of drug-resistant $A$. baumannii $24 \mathrm{~h}$ after the treatment. However, the bactericidal effect of TQ against drug-resistant $A$. baumannii was observed at a higher concentration. Interestingly, A. baumannii did not exhibit any bacterial regrowth in the presence of TQ. The antibacterial activity of TQ is suggested to be mediated through the generation of reactive oxygen species (ROS) [31]. Besides, TQ has been shown to inhibit biofilm formation in some pathogenic bacteria, including Staphylococcus aureus, Staphylococcus epidermidis, Enterococcus faecalis and Pseudomonas aeruginosa [32]. A study by Dera et al. demonstrated TQ-induced reduction in the extracellular cell wall of bacteria as revealed by electron microscopy [33]. On the other hand, amoxicillin (AMX) was highly effective against drug-sensitive A. baumannii, but not against drug-resistant $A$. baumannii as shown by the agar well diffusion, dilution and time-kill studies.

TQ has been shown to possess therapeutic effects in the treatment of various disease models [7]. However, the clinical use of TQ has been hampered because of its low solubility and bioavailability [19]. In order to increase its therapeutic efficacy, the liposome- and nanoparticle-based formulations of TQ have been shown to possess greater efficacy against various diseases $[18,24,34-36]$. In this study, we prepared TQ-incorporated liposomes to increase the activity and decrease the toxicity of the drug. Phospholipids and cholesterol are safe and are commonly used in the preparation of liposomal antibiotics and vaccines [37]. Liposomes were prepared with DPPC and cholesterol to prepare TQ-loaded liposomes. Being hydrophobic in nature, about $90 \%$ of TQ was incorporated in the lipid bilayer of the DPPC liposomes. The stability of the liposomal formulation of TQ was determined in the presence of deionized water or human serum. The findings suggested that the liposomal formulation of TQ was very stable due to a strong interaction between the lipids and TQ due to their hydrophobic nature. In order to evaluate the toxicity of TQ, free or liposomal TQ was administered to mice at the doses of 1, 10, 20 and $40 \mathrm{mg} / \mathrm{kg}$. The mice that were treated with Lip-TQ exhibited comparatively lower toxicity as compared to free TQ at the same dose (Tables 1-3). The effect of free TQ or Lip-TQ was analyzed by determining the erythrocyte, leukocyte and platelet counts in the blood of the treated mice. The mice in the group treated with free TQ at a dose of $40 \mathrm{mg} / \mathrm{kg}$ exhibited a significantly lower erythrocyte count (Table 2). Biochemical parameters, including AST, ALT, BUN and 
creatinine, were analyzed in order to assess the toxicity of TQ in terms of the liver and kidney functions. Furthermore, free TQ at a dose of $40 \mathrm{mg} / \mathrm{kg}$ caused significant liver and kidney toxicity as compared to the treatment with Lip-TQ at a comparable dose (Table 3). However, the administration of Lip-TQ $(40 \mathrm{mg} / \mathrm{kg})$ induced a moderate elevation in the AST level. These findings revealed that the incorporation of TQ in liposomes considerably reduced toxicity of the drug because liposomes slowly release encapsulated drugs into the systemic circulation as compared to the burst release of the free drug. These results are in agreement with the results of earlier studies that demonstrated increased efficacy and reduced toxicity of TQ upon incorporation in liposomes [38].

Because of the recent surfacing of multidrug-resistant isolates of A. baumannii and toxicity of antibiotics, there is a need in finding new antibiotics with greater efficacy and decreased toxicity. In the current study, we showed the activity of TQ against A. baumannii in both in vitro and in vivo studies. Importantly, TQ exhibited antibacterial activity against multidrug-resistant $A$. baumannii as shown by the agar well diffusion, dilution and timekill assays and in a murine model of systemic infection. For in vivo studies, the drugs were administered into the mice intraperitoneally. The intraperitoneal route was chosen because it is convenient, easy and less stressful for animals. Furthermore, higher volumes of formulations can be repeatedly administered. Nanoparticle formulations of the drugs have exhibited much higher bioavailability as compared to free drugs when administered intraperitoneally due to decreased clearance $[39,40]$. The results of in vivo studies were found to be very encouraging as the treatment with Lip-TQ was effective in curing the mice infected with the drug-sensitive and drug-resistant $A$. baumannii. The mice infected with drug-sensitive $A$. baumannii exhibited a $90 \%$ survival rate on day 30 after treatment with Lip-TQ (10 mg/kg), whereas the drug-resistant $A$. baumannii-infected mice had a $70 \%$ survival rate. Since TQ is poorly soluble in aqueous media, it shows poor efficacy and bioavailability in animal models. It is also substantiated by the results of the present study that demonstrated lower effectiveness of free TQ as compared to Lip-TQ in the treatment of the A. baumannii infection. The mice infected with drug-sensitive $A$. baumannii exhibited a $40 \%$ survival rate, whereas the mice infected with drug-resistant $A$. baumannii exhibited a $20 \%$ survival rate after the treatment with free TQ at a dose of $10 \mathrm{mg} / \mathrm{kg}$. The survival data were also supported by the bacterial load data, which showed the smallest number of CFUs in the mice treated with Lip-TQ at a dose of $10 \mathrm{mg} / \mathrm{kg}$. This suggested that the incorporation of TQ in liposomes increased its efficacy and bioavailability. Lung tissues contain an abundance of reticuloendothelial system (RES) cells. One of the important properties of liposomes is that they are avidly taken by cells of the RES. Thus, liposomes seem to be an important drug delivery system that can be successfully exploited to treat lung infections [41]. AMX exhibits broad-spectrum activity and is one of the most commonly used antibiotics to treat both Gram-positive and Gram-negative bacterial infections. This is also supported by the results of the present study that shows the most reduced bacterial load in lung tissues of the mice treated with Lip-TQ. In the current study, AMX was used as a control antibiotic to treat both drug-sensitive and drug-resistant $A$. baumannii infection in mice. AMX was found to be very effective against drug-sensitive A. baumannii and the infected mice treated with AMX at a dose of $10 \mathrm{mg} / \mathrm{kg}$ exhibited a $100 \%$ survival rate. On the contrary, AMX was ineffective against drug-resistant $A$. baumannii at the same dose. This suggested that TQ, particularly Lip-TQ, may prove an important formulation to treat drug-resistant $A$. baumannii.

The effect of treatment on the alleviation of the $A$. baumannii infection was evaluated by analyzing the total leukocyte and neutrophils counts in the blood, the levels of inflammatory markers such as the CRP and PCT. Leukocytes, particularly neutrophils, are the first responders to acute bacterial infections [42]. Leukocytes and neutrophils feature a sharp increase in acute bacterial infections. The findings of the present study demonstrated that the untreated A. baumannii-infected mice exhibited significantly higher leukocyte and neutrophil counts as compared to the uninfected normal control mice. Treatment with Lip-TQ considerably alleviated the A. baumannii infection and the treated mice exhibited 
lower leukocyte and neutrophil counts. Interestingly, neutral liposomes have not been shown to interact with leukocytes and alter their numbers in the systemic circulation [43]. AMX treatment significantly reduced the leukocyte and neutrophil counts in the mice infected with drug-sensitive A. baumannii. On the other hand, AMX could not alleviate the leukocyte and neutrophil counts in the mice infected with drug-resistant $A$. baumannii.

The CRP and PCT, blood biomarkers in the diagnosis of bacterial infections, are highly elevated in bacterial infections and inflammations [44]. The findings of the current study showed highly elevated levels of the CRP and PCT in the blood of the A. baumannii-infected mice. The A. baumannii infection has been shown to induce systemic inflammation by virtue of releasing its outer membrane vesicles [45]. Moreover, the production of proinflammatory cytokines in response to $A$. baumannii further aggravates inflammation in the infected mice [46]. Because of substantial elimination of the A. baumannii infection in the Lip-TQtreated mice, there were reduced levels of the CRP and PCT in the blood of the treated mice. TQ is a well-known anti-inflammatory agent and has a therapeutic role in the treatment of many inflammatory diseases [6,9]. In addition to its antibacterial activity against $A$. baumannii, the anti-inflammatory effect of TQ may have an important role in the mitigation of the CRP and PCT levels. At the same time, the treatment with AMX was ineffective against drug-resistant $A$. baumannii and could not alleviate the blood levels of the CRP and PCT.

\section{Conclusions}

A liposomal formulation of TQ was prepared and evaluated against $A$. baumannii both in vitro and in a mouse model. Lip-TQ exhibited greater activity against the drug-sensitive and drug-resistant $A$. baumannii as compared to the activity of free TQ at the respective doses. The greater activity of Lip-TQ was substantiated by the increased survival rate and reduced bacterial load in lung tissues of the treated mice. Moreover, the leukocyte, neutrophil, CRP and PCT levels were significantly reduced in the A. baumannii-infected mice treated with Lip-TQ, particularly at a dose of $10 \mathrm{mg} / \mathrm{kg}$. The greater activity of Lip-TQ is attributed to the property of liposomes to release the incorporated drugs into the blood at the constant and sustained level. Moreover, it also results in the reduced toxicity of the drug. AMX was used as a control drug and was highly effective in the treatment of the drug-sensitive A. baumannii infection in mice. However, the treatment with AMX could not cure the drug-resistant $A$. baumannii infection. Collectively, these findings indicated that Lip-TQ may prove to be an effective therapeutic formulation in the treatment of the drug-sensitive or drug-resistant $A$. baumannii infection.

Author Contributions: Conceptualization, K.S.A.; Data curation, H.K.; A.K. and M.A.K.; Funding acquisition, H.Y. and M.A.K.; Investigation, K.S.A.; A.A. (Ahmad Almatroudi); H.K. and H.Y.; Methodology, A.A. (Aseel Aljaghwani); A.K. and M.A.K.; Project administration, A.M.A. and F.A.; Supervision, M.A.K.; Writing—original draft, K.S.A. and M.A.K.; Writing—review \& editing, A.K. All authors have read and agreed to the published version of the manuscript.

Funding: This work is supported by the grant \# 5604-cams1-2019-2-2-I from the Deanship of Scientific Research, Qassim University to Khaled Allemailem.

Institutional Review Board Statement: The study entitled "Safety and Therapeutic Efficacy of Thymoquinone-Loaded Liposomes against Drug-Sensitive and Drug-Resistant Acinetobacter baumannii" is approved under the No. 5604-cams1-2019-2-2-I.

Informed Consent Statement: Not applicable.

Data Availability Statement: All relevant data have been provided within the manuscript. There are no supporting files and no data was held.

Acknowledgments: The authors gratefully acknowledge the Deanship of Scientific Research, Qassim University, for the financial support of this research study under the Interdisciplinary Grant (No. 5604-cams1-2019-2-2-I) during the 2019 academic year.

Conflicts of Interest: The authors declare no conflict of interest. 


\section{References}

1. Lin, M.F.; Lan, C.Y. Antimicrobial resistance in Acinetobacter baumannii: From bench to bedside. World J. Clin Cases. 2014, 2, 787-814. [CrossRef] [PubMed]

2. Ibrahim, M.E. Prevalence of Acinetobacter baumannii in Saudi Arabia: Risk factors, antimicrobial resistance patterns and mechanisms of carbapenem resistance. Ann. Clin. Microbiol. Antimicrob. 2019, 18, 1. [CrossRef] [PubMed]

3. World Health Organization. Central Asian and Eastern European Surveillance of Antimicrobial Resistance. Annual Report 2017; World Health Organization Regional Office for Europe: Copenhagen, Denmark, 2017.

4. Aly, M.; Tayeb, H.T.; Al Johani, S.M.; Alyamani, E.J.; Aldughaishem, F.; Alabdulkarim, I.; Balkhy, H.H. Genetic diversity of OXA-51-like genes among multidrug-resistant Acinetobacter baumannii in Riyadh, Saudi Arabia. Eur. J. Clin. Microbiol. Infect Dis. 2014, 33, 1223-1228. [CrossRef] [PubMed]

5. Lee, C.R.; Lee, J.H.; Park, M.; Park, K.S.; Bae, I.K.; Kim, Y.B.; Cha, C.J.; Jeong, B.C.; Lee, S.H. Biology of Acinetobacter baumannii: Pathogenesis, Antibiotic Resistance Mechanisms, and Prospective Treatment Options. Front. Cell Infect Microbiol. $2017,7,55$. [CrossRef] [PubMed]

6. Saeed, N.K.; Kambal, A.M.; El-Khizzi, N.A. Antimicrobial-resistant bacteria in a general intensive care unit in Saudi Arabia. Saudi. Med. J. 2010, 31, 1341-1349.

7. Khan, M.A.; Younus, H. Thymoquinone Shows the Diverse Therapeutic Actions by Modulating Multiple Cell Signaling Pathways: Single Drug for Multiple Targets. Curr. Pharm. Biotechnol. 2018, 19, 934-945. [CrossRef]

8. Rahmani, A.H.; Alzohairy, M.A.; Khan, M.A.; Aly, S.M. Therapeutic Implications of Black Seed and Its Constituent Thymoquinone in the Prevention of Cancer through Inactivation and Activation of Molecular Pathways. Evid Based Complement Alternat Med. 2014, 2014, 724658. [CrossRef]

9. Khan, M.A. Thymoquinone, a constituent of prophetic medicine-black seed, is a miracle therapeutic molecule against multiple diseases. Int. J. Health Sci. 2019, 13, 1-2.

10. Majdalawieh, A.F.; Fayyad, M.W. Immunomodulatory and anti-inflammatory action of Nigella sativa and thymoquinone: A comprehensive review. Int. Immunopharmacol. 2015, 28, 295-304. [CrossRef]

11. Miao, X.; Liu, H.; Zheng, Y.; Guo, D.; Shi, C.; Xu, Y.; Xia, X. Inhibitory Effect of Thymoquinone on Listeria monocytogenes ATCC 19115 Biofilm Formation and Virulence Attributes Critical for Human Infection. Front. Cell Infect Microbiol. 2019, 9, 304. [CrossRef]

12. Randhawa, M.A.; Gondal, M.A.; Al-Zahrani, A.H.; Rashid, S.G.; Ali, A. Synthesis, morphology and antifungal activity of nano-particulated amphotericin-B, ketoconazole, and thymoquinone against Candida albicans yeasts and Candida biofilm. J. Environ. Sci. Health A Tox. Hazard Subst. Environ. Eng. 2015, 50, 119-124. [CrossRef]

13. Tantivitayakul, P.; Kaypetch, R.; Muadchiengka, T. Thymoquinone inhibits biofilm formation and virulence properties of periodontal bacteria. Arch Oral Biol. 2020, 115, 104744. [CrossRef] [PubMed]

14. Paster, B.J.; Boches, S.K.; Galvin, J.L.; Ericson, R.E.; Lau, C.N.; Levanos, V.A.; Sahasrabudhe, A.; Dewhirst, F.E. Bacterial diversity in human subgingival plaque. J. Bacteriol. 2001, 183, 3770-3783.

15. Khan, M.A. Antimicrobial actions of thymoquinone. In Molecular and Therapeutic Actions of Thymoquinone; Younus, H., Ed.; Springer: Berlin/Heidelberg, Germany, 2018; pp. 57-64.

16. Khan, M.A. Targeted Drug Delivery Using Tuftsin-bearing Liposomes: Implications in the treatment of infectious diseases and tumors. Curr. Drug Targets. 2020, 22, 770-778. [CrossRef] [PubMed]

17. Zukancic, D.; Suys, E.J.A.; Pilkington, E.H.; Algarni, A.; Al-Wassiti, H.; Truong, N.P. The Importance of Poly(ethylene glycol) and Lipid Structure in Targeted Gene Delivery to Lymph Nodes by Lipid Nanoparticles. Pharmaceutics 2020, 12, 1068. [CrossRef] [PubMed]

18. Odeh, F.; Ismail, S.I.; Abu-Dahab, R.; Mahmoud, I.S.; Al Bawab, A. Thymoquinone in liposomes: A study of loading efficiency and biological activity towards breast cancer. Drug Deliv. 2012, 19, 371-377. [CrossRef] [PubMed]

19. Rajput, S.; Puvvada, N.; Kumar, B.N.; Sarkar, S.; Konar, S.; Bharti, R.; Dey, G.; Mazumdar, A.; Pathak, A.; Fisher, P.B.; et al. Overcoming Akt Induced Therapeutic Resistance in Breast Cancer through siRNA and Thymoquinone Encapsulated Multilamellar Gold Niosomes. Mol. Pharm. 2015, 12, 4214-4225. [CrossRef]

20. Khan, M.A.; Aljarbou, A.N.; Khan, A.; Younus, H. Liposomal thymoquinone effectively combats fluconazole-resistant Candida albicans in a murine model. Int. J. Biol. Macromol. 2015, 76, 203-208. [CrossRef] [PubMed]

21. Clinical and Laboratory Standards Institute. Performance Standards for Antimicrobial Susceptibility Testing: Twenty-Sixth Informational Supplement M100-S26; CLSI: Wayne, PA, USA, 2016.

22. Hombach, M.; Jetter, M.; Blöchliger, N.; Kolesnik-Goldmann, N.; Böttger, E.C. Fully automated disc diffusion for rapid antibiotic susceptibility test results: A proof-of-principle study. J. Antimicrob. Chemother. 2017, 72, 1659-1668. [CrossRef] [PubMed]

23. Parra-Millán, R.; Vila-Farrés, X.; Ayerbe-Algaba, R.; Varese, M.; Sánchez-Encinales, V.; Bayó, N.; Pachón-Ibáñez, M.E.; Teixidó, M.; Vila, J.; Pachón, J.; et al. Synergistic activity of an OmpA inhibitor and colistin against colistin-resistant Acinetobacter baumannii: Mechanistic analysis and in vivo efficacy. J. Antimicrob. Chemother. 2018, 73, 3405-3412. [CrossRef]

24. Khan, M.A.; Aldebasi, Y.H.; Alsuhaibani, S.A.; Alsahli, M.A.; Alzohairy, M.A.; Khan, A.; Younus, H. Therapeutic potential of thymoquinone liposomes against the systemic infection of Candida albicans in diabetic mice. PLoS ONE 2018, 13, e0208951. [CrossRef] 
25. Khan, S.H.; Younus, H.; Allemailem, K.S.; Almatroudi, A.; Alrumaihi, F.; Alruwetei, A.M.; Alsahli, M.A.; Khan, A.; Khan, M.A. Potential of Methylglyoxal-Conjugated Chitosan Nanoparticles in Treatment of Fluconazole-Resistant Candida albicans Infection in a Murine Model. Int. J. Nanomed. 2020, 15, 3681-3693. [CrossRef]

26. Maswadeh, H.M.; Aljarbou, A.N.; Alorainy, M.S.; Rahmani, A.H.; Khan, M.A. Coadministration of doxorubicin and etoposide loaded in camel milk phospholipids liposomes showed increased antitumor activity in a murine model. Int. J. Nanomedicine. 2015, 10, 2847-2855. [CrossRef] [PubMed]

27. Khan, M.A.; Khan, A.; Khan, S.H.; Azam, M.; Khan, M.M.U.; Khalilullah, H.; Younus, H. Coadministration of liposomal methylglyoxal increases the activity of amphotericin B against Candida albicans in leukopoenic mice. J. Drug Target 2020, 6, 1-10. [CrossRef]

28. Su, X.Z.; Zhang, X.; Chen, Y.; Tomofusa, T. Multiple resistance in Acinetobacter baumannii ATCC 19606 and cloning of genes responsible for the resistance. Chin. J. Antibiot. 2006, 31, 688-691.

29. World Health Organization. WHO Publishes of Bacteria for Which New Antibiotics are Urgently Needed. Available online: http:/ / www.who.int/mediacentre/news/release/2017/bacteria-antibiotics-needed/fr/ (accessed on 15 August 2019).

30. Ayoub, M.C.; Hammoudi, H.D. Insights into Acinetobacter baumannii: A Review of Microbiological, Virulence, and Resistance Traits in a Threatening Nosocomial Pathogen. Antibiotics 2020, 9, 119. [CrossRef]

31. Goel, S.; Mishra, P. Thymoquinone inhibits biofilm formation and has selective antibacterial activity due to ROS generation. Appl. Microbiol. Biotechnol. 2018, 102, 1955-1967. [CrossRef]

32. Chaieb, K.; Kouidhi, B.; Jrah, H.; Mahdouani, K.; Bakhrouf, A. Antibacterial activity of Thymoquinone, an active principle of Nigella sativa and its potency to prevent bacterial biofilm formation. BMC Complement Altern. Med. 2011, 11, 29. [CrossRef]

33. Dera, A.A.; Ahmad, I.; Rajagopalan, P.; Shahrani, M.A.; Saif, A.; Alshahrani, M.Y.; Alraey, Y.; Alamri, A.M.; Alasmari, S.; Makkawi, M.; et al. Synergistic efficacies of thymoquinone and standard antibiotics against multi-drug resistant isolates. Saudi Med. J. 2021, 42, 196. [CrossRef]

34. Laskar, A.A.; Khan, M.A.; Rahmani, A.H.; Fatima, S.; Younus, H. Thymoquinone, an active constituent of Nigella sativa seeds, binds with bilirubin and protects mice from hyperbilirubinemia and cyclophosphamide-induced hepatotoxicity. Biochimie 2016, 127, 205-213. [CrossRef]

35. Fahmy, H.M.; Saad, E.A.E.S.; Sabra, N.M.; El-Gohary, A.A.; Mohamed, F.F.; Gaber, M.H. Treatment merits of Latanoprost/ThymoquinoneEncapsulated liposome for glaucomatus rabbits. Int. J. Pharm. 2018, 548, 597-608. [CrossRef]

36. Mostafa, M.; Alaaeldin, E.; Aly, U.F.; Sarhan, H.A. Optimization and Characterization of Thymoquinone-Loaded Liposomes with Enhanced Topical Anti-inflammatory Activity. AAPS Pharmscitech 2018, 19, 3490-3500. [CrossRef]

37. Vu, M.N.; Kelly, H.G.; Tan, H.X.; Juno, J.A.; Esterbauer, R.; Davis, T.P.; Truong, N.P.; Wheatley, A.K.; Kent, S.J. Hemagglutinin Functionalized Liposomal Vaccines Enhance Germinal Center and Follicular Helper T Cell Immunity. Adv. Healthc. Mater. 2021, e2002142. [CrossRef]

38. Yong, Y.S.; Saiful Yazan, L.; Ng, W.K.; Noordin, M.M.; Sapuan, S.; Foo, J.B.; Tor, Y.S. Acute and subacute toxicity profiles of thymoquinone-loaded nanostructured lipid carrier in BALB/c mice. Int. J. Nanomed. 2016, 11, 5905-5915. [CrossRef] [PubMed]

39. Dimer, F.A.; Pigatto, M.C.; Boque, C.A.; Pase, C.S.; Roversi, K.; Pohlmann, A.R.; Burger, M.E.; Rates, M.K.; Dalla Costa, T.; Guterres, S.S. Nanoencapsulation Improves Relative Bioavailability and Antipsychotic Effect of Olanzapine in Rats. J. Biomed. Nanotechnol. 2015, 11, 1482-1493. [CrossRef] [PubMed]

40. Badran, M.M.; Alomrani, A.H.; Harisa, G.I.; Ashour, A.E.; Kumar, A.; Yassin, A.E. Novel docetaxel chitosan-coated PLGA/PCL nanoparticles with magnified cytotoxicity and bioavailability. Biomed. Pharm. 2018, 106, 1461-1468. [CrossRef]

41. Alipour, M.; Suntres, Z.E. Liposomal antibiotic formulations for targeting the lungs in the treatment of Pseudomonas aeruginosa. Ther. Deliv. 2014, 5, 409-427. [CrossRef]

42. Kobayashi, S.D.; Malachowa, N.; DeLeo, F.R. Neutrophils and Bacterial Immune Evasion. J. Innate Immun. 2018, $10,432-441$. [CrossRef]

43. Vu, M.N.; Kelly, H.G.; Wheatley, A.K.; Peng, S.; Pilkington, E.H.; Veldhuis, N.A.; Davis, T.P.; Kent, S.J.; Truong, N.P. Cellular Interactions of Liposomes and PISA Nanoparticles during Human Blood Flow in a Microvascular Network. Small 2020, 16, e2002861. [CrossRef] [PubMed]

44. Tang, J.H.; Gao, D.P.; Zou, P.F. Comparison of serum PCT and CRP levels in patients infected by different pathogenic microorganisms: A systematic review and meta-analysis. Braz. J. Med. Biol. Res. 2018, 51, e6783. [CrossRef]

45. Marion, C.R.; Lee, J.; Sharma, L.; Park, K.S.; Lee, C.; Liu, W.; Liu, P.; Feng, J.; Gho, Y.S.; Dela Cruz, C.S. Toll-Like Receptors 2 and 4 Modulate Pulmonary Inflammation and Host Factors Mediated by Outer Membrane Vesicles Derived from Acinetobacter baumannii. Infect. Immun. 2019, 87, e00243-19. [CrossRef]

46. Harris, G.; KuoLee, R.; Xu, H.H.; Chen, W. Acute intraperitoneal infection with a hypervirulent Acinetobacter baumannii isolate in mice. Sci. Rep. 2019, 9, 6538. [CrossRef] [PubMed] 